\title{
Article \\ Influence of Coating and Size of Magnetic Nanoparticles on Cellular Uptake for In Vitro MRI
}

\author{
Belén Cortés-Llanos ${ }^{1,2,3}{ }^{\oplus}$, Sandra M. Ocampo ${ }^{1}$, Leonor de la Cueva ${ }^{1}$, Gabriel F. Calvo ${ }^{4}$, Juan Belmonte-Beitia ${ }^{4}{ }^{(0)}$, \\ Lucas Pérez 1,3 , Gorka Salas $1, * \mathbb{1}$ and Ángel Ayuso-Sacido $5,6,7, * \mathbb{1}$ \\ 1 IMDEA Nanoscience, Ciudad Universitaria de Cantoblanco, 28049 Madrid, Spain; \\ belencortess@ucm.es (B.C.-L.); samioca75@gmail.com (S.M.O.); ldelacueva@euro-funding.com (L.d.1.C.); \\ lucas.perez@ucm.es (L.P.) \\ 2 Department of Bioengineering, University of Washington, Seattle, WA 98195, USA \\ 3 Department of Materials Physics, Complutense University of Madrid, 28040 Madrid, Spain \\ 4 MOLAB-Mathematical Oncology Laboratory, Department of Mathematics, Universidad de Castilla-La Mancha, \\ 13071 Ciudad Real, Spain; gabriel.fernandez@uclm.es (G.F.C.); juan.belmonte@uclm.es (J.B.-B.) \\ 5 Brain Tumor Laboratory, Fundación Vithas, Grupo Hospitales Vithas, 28043 Madrid, Spain \\ 6 Faculty of Experimental Sciences, Universidad Francisco de Vitoria, 28223 Madrid, Spain \\ 7 Faculty of Medicine, Universidad Francisco de Vitoria, 28223 Madrid, Spain \\ * Correspondence: gorka.salas@imdea.org (G.S.); ayusosacido@gmail.com (Á.A.-S.); \\ Tel.: +34-912-998-850 (G.S.); +34-686-966-904 (Á.A.-S.)
}

Citation: Cortés-Llanos, B.; Ocampo, S.M.; de la Cueva, L.; Calvo, G.F.; Belmonte-Beitia, J.; Pérez, L.; Salas, G.; Ayuso-Sacido, Á. Influence of Coating and Size of Magnetic Nanoparticles on Cellular Uptake for In Vitro MRI. Nanomaterials 2021, 11, 2888. https:// doi.org/10.3390/nano11112888

Academic Editor: Alessandro Barge

Received: 19 September 2021

Accepted: 22 October 2021

Published: 28 October 2021

Publisher's Note: MDPI stays neutral with regard to jurisdictional claims in published maps and institutional affiliations.

Copyright: (c) 2021 by the authors. Licensee MDPI, Basel, Switzerland. This article is an open access article distributed under the terms and conditions of the Creative Commons Attribution (CC BY) license (https:// creativecommons.org/licenses/by/ $4.0 /)$.

\begin{abstract}
Iron oxide nanoparticles (IONPs) are suitable materials for contrast enhancement in magnetic resonance imaging (MRI). Their potential clinical applications range from diagnosis to therapy and follow-up treatments. However, a deeper understanding of the interaction between IONPs, culture media and cells is necessary for expanding the application of this technology to different types of cancer therapies. To achieve new insights of these interactions, a set of IONPs were prepared with the same inorganic core and five distinct coatings, to study their aggregation and interactions in different physiological media, as well as their cell labelling efficiency. Then, a second set of IONPs, with six different core sizes and the same coating, were used to study how the core size affects cell labelling and MRI in vitro. Here, IONPs suspended in biological media experience a partial removal of the coating and adhesion of molecules. The FBS concentration alters the labelling of all types of IONPs and hydrodynamic sizes $\geq 300 \mathrm{~nm}$ provide the greatest labelling using the centrifugation-mediated internalization (CMI). The best contrast for MRI results requires a core size range between 12-14 nm coated with dimercaptosuccinic acid (DMSA) producing $R_{2}{ }^{*}$ values of $393.7 \mathrm{~s}^{-1}$ and $428.3 \mathrm{~s}^{-1}$, respectively. These findings will help to bring IONPs as negative contrast agents into clinical settings.
\end{abstract}

Keywords: iron oxide nanoparticles; colloidal properties; cellular uptake; magnetic resonance imaging

\section{Introduction}

In vitro and in vivo nanoparticle (NP)-cell labelling, and tracking have become very promising techniques in biomedicine due to their clinical applications, spanning from regenerative medicine to the diagnosis and treatment of several diseases [1-3]. Among other nanomaterials, superparamagnetic iron oxide nanoparticles (IONPs) attract special attention because they can be remotely actuated through the application of magnetic fields that can easily penetrate in tissues [4,5]. IONPs are already used for the treatment of different tumors, mainly prostate [6] and glioblastoma [7], as well as contrast agents in magnetic resonance imaging (MRI) or magnetic particle imaging (MPI) and, in general, are considered to be relatively safe [8]. Their use has been approved in humans within clinical assay context to test enhancement of MRI diagnostic for different type of cancers [9-16], Multiple Sclerosis [17,18], myocardial infarction [19,20], vascular Inflammation in migraine 
without Aura [21], and inflammatory cell labelling and tracking with MRI after myocardial infarction [22]. However, increasing the intracellular internalization in a significantly faster and controlled way, both in vitro and in vivo, remains one of the major challenges to fully translate and exploit their capabilities in the clinical practice [23-25]. A handy approach for enhancing the uptake of nanoparticles (NPs) by cells in very short times is the centrifugation-mediated internalization (CMI) [26]. CMI has been applied for labelling living cells with high efficiency in a few minutes. Recently, experimental results using the CMI and other classical methods, together with numerical simulations of different transport mathematical models, provided evidence that the colloidal properties of IONPs have a strong influence on their internalization by cells, and that the coating of IONPs plays an important role in this process [27].

IONPs are usually composed of a magnetic core of iron oxide, typically magnetite $\left(\mathrm{Fe}_{3} \mathrm{O}_{4}\right)$ or maghemite $\left(\gamma-\mathrm{Fe}_{2} \mathrm{O}_{3}\right)$, and a hydrophilic coating to enhance their stability in aqueous suspension and their biocompatibility [28,29]. The magnetic properties of IONPs are size-dependent, so their behavior as MRI contrast agents depends strongly on their size [30]. IONPs are often employed for $T_{2}{ }^{*}$-weighted MRI, and their contrast efficiency tend to increase with the size of the magnetic core [31]. IONPs in physiological media are usually aggregated and the characteristics of that aggregation, including, the aggregate size, also have an impact on the MRI contrast enhancement of IONPs [32]. Aggregation is common when IONPs are dispersed in liquid media and is almost unavoidable in physiological media [33]. It is influenced by the core size and, especially, by the surface coating and the dispersion media [34]. Therefore, the IONPs' core size and coating are key features to be considered for cell labelling and tracking by MRI.

Because of this, we have studied the influence of the core size and the coating of IONPs on the cell labelling efficiency by the CMI method, and on the MRI contrast enhancement in cell cultures. Firstly, we fixed the NPs core size and used five different coatings to assess what is the influence of the coating on the stability of IONPs in different cell culture media, as well as their interaction and aggregation with the media and on their internalization through the CMI method. Once we observed which was the coating presenting the higher labelling efficiency with good viability, we decided to fix the coating and change the core size. Then, IONPs with the same coating and six distinct core sizes were used to quantify the influence of the core size in the cell internalization and MRI. This study will open a new source of information regarding IONPs characterization to improve the labelling for MRI contrast enhancement.

\section{Materials and Methods}

\subsection{Materials}

Iron(III) chloride (27\% aqueous solution, with density $1.26 \mathrm{~kg} / \mathrm{L}$, VWR, Radnor, PA, USA), iron(II) chloride tetrahydrate ( $\geq 99.0 \%$, Fluka, Charlotte, NC, USA), iron(III) acetylacetonate $(97 \%$, Sigma-Aldrich, St. Louis, MO, USA), ammonium hydroxide solution ( $25 \%$ in water, Fluka), iron(III) nitrate nonahydrate ( $\geq 98.0 \%$, Fluka), sodium oleate ( $\geq 82 \%$, Sigma-Aldrich, St. Louis, MO, USA), oleic acid ( $90 \%$, Aldrich), oleylamine $(70 \%$, Aldrich), 1,2-dodecanediol (90\%, Aldrich), 1-octadecene (90\%, Aldrich), n-hexane (99\%, Scharlau, Barcelona, Spain), toluene (99.8\%, Sigma-Aldrich), dimethyl sulfoxide ( $>99.5 \%$, Sigma-Aldrich) and ethanol (96\%, Panreac, Barcelona, Spain), meso-2,3-dimercaptosuccinic acid (DMSA, 98\% Aldrich), dextran (from Leuconostoc spp., Mr 40,000, Sigma-Aldrich, St. Louis, MO, USA), carboxymethyl-dextran sodium salt (10,000-20,000 Dalton, Sigma), diethylaminoethyl-dextran (average mol wt 40,000, Sigma), meso-2,3-dimercaptosuccinic acid ( 98\%, Aldrich), and (3-aminopropyl) triethoxysilane (98\%, Alfa Aesar, Ward Hill, MA, USA) were used for the synthesis of IONPs. Dialysis tubing cellulose membranes were purchased from Sigma and washed before use. Phosphate buffered saline solution (PBS, 1x), Dulbecco's modified eagle's medium (DMEM), fetal bovine serum (FBS), Lglutamine, fungizone and antibiotics were purchased from GIBCO (Waltham, MA, USA). For the viability, the Resazurin dye was purchased from Sigma-Aldrich. Paraformalde- 
hyde, nitric acid, hydrochloric acid and agarose were purchased from Sigma-Aldrich. For Prussian blue staining, potassium ferrocyanide ( $4 \%$, Sigma-Aldrich), hydrochloric acid ( $4 \%$ Sigma-Aldrich), neutral red (0.5\%, Panreac Quimica S.L.U, Barcelona, Spain), coverslips (GmbH \& Co. KG, Maienfeld, Switzerland) and DePeX (SERVA Electrophoresis GmbH, Heidelberg, Germany).

\subsection{IONPs Synthesis and Characterization}

IONPs with the same core and different coatings were synthesized by the coprecipitation method, following the Massart's method with slight modifications [35]. A total of $43 \mathrm{~mL}$ of ferric chloride $27 \%$ aqueous solution $(0.090 \mathrm{~mol})$ was diluted with $400 \mathrm{~mL}$ of water in a $1 \mathrm{~L}$-beaker equipped with a magnetic stirrer. The solution was vigorously stirred $(1200 \mathrm{rpm})$ and $\mathrm{FeCl}_{2} \cdot 4 \mathrm{H}_{2} \mathrm{O}(10.8 \mathrm{~g}, 0.054 \mathrm{~mol})$ added. The orange solution was again diluted with $100 \mathrm{~mL}$ of water before slowly adding (addition time: $4 \mathrm{~min}$ ) an aqueous solution of $\mathrm{NH}_{4} \mathrm{OH} 25 \%(75 \mathrm{~mL})$. The solution turned black immediately due to the formation of magnetite $\left(\mathrm{Fe}_{3} \mathrm{O}_{4}\right)$ NPs. After $5 \mathrm{~min}$, the reaction mixture was heated until $90{ }^{\circ} \mathrm{C}$ and kept $3 \mathrm{~h}$ at that temperature. The reaction was allowed to cool down to room temperature and the black solid separated from the liquid with the help of a magnet (magnetic decantation). The solid was washed 3 times with water ( 3 times, $300 \mathrm{~mL}$ ), stirred for $15 \mathrm{~min}$ and separated from the liquid by magnetic decantation.

Subsequently, the sample was subjected to acid treatment, as previously described [36], in order to oxidize $\mathrm{Fe}_{3} \mathrm{O}_{4}$ to $\gamma-\mathrm{Fe}_{2} \mathrm{O}_{3}$ and provide stability against oxidation [37]. A reddishbrown solid was obtained and redispersed in water $(135 \mathrm{~mL})$ for long-term storage $\left(4^{\circ} \mathrm{C}\right)$. The Fe concentration of this stock dispersion was determined by ICP-OES $(70 \mathrm{mg} / \mathrm{mL})$. The percentage yield was based on Fe measured by ICP and reached $70 \%$.

\subsubsection{Dextran Coating of IONPs (NP-D)}

A solution of $\mathrm{NaOH}(50 \mathrm{mg}, 1.25 \mathrm{mmol})$ in water $(0.5 \mathrm{~mL})$ was added to $2 \mathrm{~mL}$ of the stock dispersion of IONPs. The dispersion contained $200 \mathrm{mg}$ of $\gamma-\mathrm{Fe}_{2} \mathrm{O}_{3}(140 \mathrm{mg}$ of $\mathrm{Fe}$ based on ICP) and is $0.5 \mathrm{M}$ in NaOH. A solution of dextran $(200 \mathrm{mg})$ in water $(2.5 \mathrm{~mL})$ was then added and the mixture sonicated for $10 \mathrm{~h}$. Finally, the NPs were dialyzed for 3 days to remove impurities [38]. Yield $=86 \%$.

\subsubsection{Diethylaminoethyl-dextran Coating of IONPs (NP-AD)}

A total of $2 \mathrm{~mL}$ ( $200 \mathrm{mg}$ of $\gamma-\mathrm{Fe}_{2} \mathrm{O}_{3}$ ) of the stock dispersion of IONPs were diluted with a solution of $\mathrm{NaOH}(50 \mathrm{mg}, 1.25 \mathrm{mmol})$ in $16 \mathrm{~mL}$ of water to give a dispersion with $\mathrm{pH}=12$ that was then slowly added to another solution of diethylaminoethyl-dextran (200 mg) in $12 \mathrm{~mL}$ of water. The mixture was sonicated for $10 \mathrm{~h}$ and finally dialyzed for 3 days to remove impurities [39]. Yield $=79 \%$.

\subsubsection{Carboxymethyl-dextran Coating of IONPs (NP-CMD)}

A solution of carboxymethyl-dextran $(200 \mathrm{mg})$ in water $(2.5 \mathrm{~mL})$ was added to $2 \mathrm{~mL}$ (200 mg of $\gamma-\mathrm{Fe}_{2} \mathrm{O}_{3}$ ) of the stock dispersion of NPs previously diluted with $0.5 \mathrm{~mL}$ of water. Then $\mathrm{HNO}_{3}(65 \%)$ was carefully added until $\mathrm{pH}=3$, the mixture sonicated for $10 \mathrm{~h}$ and then dialyzed for 3 days [40].

\subsection{4. (3-Aminopropyl) Triethoxysilane Coating of IONPs (NP-APS)}

A total of $4.2 \mathrm{~mL}$ ( $410 \mathrm{mg}$ of $\gamma-\mathrm{Fe}_{2} \mathrm{O}_{3}$ ) of the stock dispersion of IONPs were diluted with $9.8 \mathrm{~mL}$ of water and $14 \mathrm{~mL}$ of methanol. Then, under vigorous magnetic stirring, APS (1.71 mL, $7.3 \mathrm{mmol}$ ) was slowly added (addition time: $2 \mathrm{~min}$ ). After $20 \mathrm{~h}$, methanol was removed in a rotary evaporator and the resulting aqueous dispersion dialyzed for 5 days [41]. Yield $=82 \%$. 


\subsubsection{Dimercaptosuccinic Acid Coating of IONPs (NP-DMSA)}

DMSA $(10 \mathrm{mg}, 0.055 \mathrm{mmol})$ was added to $0.910 \mathrm{~mL}\left(86 \mathrm{mg}\right.$ of $\left.\gamma-\mathrm{Fe}_{2} \mathrm{O}_{3}\right)$ of the stock dispersion of IONPs, previously diluted with water to a volume of $20 \mathrm{~mL}$, and the mixture sonicated for $2 \mathrm{~h}$. Then, $\mathrm{KOH} 1 \mathrm{M}$ was added to reach $\mathrm{pH}=11$ and the sample dialyzed in water for 4 days [41]. Yield $=69 \%$.

IONPs for comparing the different core sizes with the same coating were synthesized by thermal decomposition in 1-octadecene, following the method reported by Park et al. [42,43] with some modifications [44,45]. NPs of $7 \mathrm{~nm}$ were synthesized using $\mathrm{Fe}(\mathrm{acac})_{3}(5 \mathrm{mmol})$ as iron precursor, and with oleic acid $(15 \mathrm{mmol})$, oleylamine $(15 \mathrm{mmol})$ and 1,2-dodecanediol $(25 \mathrm{mmol})$ as surfactants for the high temperature decomposition in 1-octadecene $(50 \mathrm{~mL})$. IONPs with larger sizes $(12,14,18,23,33 \mathrm{~nm})$ were synthesized using an iron(III)-oleate precursor $(10 \mathrm{mmol})$ thermally decomposed at reflux in 1-octadecene $(100 \mathrm{~mL})$ in the presence variable amounts of oleic acid and different heating rates for the different core sizes. The so-obtained hydrophobic IONPs were coated with DMSA and transferred to aqueous suspension [44].

\subsection{IONPs Characterization}

\subsubsection{Colloidal Characterization}

Hydrodynamic sizes $D_{\text {hyd }}$ in this work refer to the Z-average value measured by dynamic light scattering (DLS) from dilute suspensions of the samples in water at $\mathrm{pH} 7.4$ or in Dulbecco's modified eagle's medium (DMEM) or DMEM supplemented with $10 \%$ fetal bovine serum (FBS) when specified, in a standard cuvette, using a Zetasizer Nano ZS device (Malvern Panalytical, Worcestershire, UK). The energy source was a laser emitting red light $(633 \mathrm{~nm})$, with an angle of $173^{\circ}$ between the sample and the detector. Surface charges were evaluated by measuring the zeta-potential $\zeta$ values of samples diluted in aqueous $\mathrm{KNO}_{3} 0.01 \mathrm{M}$ (or in DMEM or DMEM supplemented with $10 \%$ of FBS), with the same Zetasizer Nano ZS device.

\subsubsection{Thermogravimetric Analysis}

The percentage weight of the organic coating was obtained by thermogravimetric/differential thermal analysis (TGA/DTA) carried out in a TA Instruments (New Castle, DE, USA) TGA 500 apparatus, with a heating rate of $10^{\circ} \mathrm{C} / \mathrm{min}$ from room temperature to $1000{ }^{\circ} \mathrm{C}$ in air atmosphere. For this analysis, aqueous samples were lyophilized to obtain the corresponding powders. TGA after incubation in different cell culture media (DMEM and DMEM + 10\% FBS) and FBS, was performed using the following protocol: $1 \mathrm{~mL}$ of IONPs dispersion in biological medium (Fe concentration $=1 \mathrm{mg} / \mathrm{mL}$ ) was mechanically stirred during $30 \mathrm{~min}$. Then, the sample was centrifuged for $10 \mathrm{~min}$ at 13,000 rpm and the supernatant was removed. After that, the IONPs were redispersed in $1 \mathrm{~mL}$ of the same biological medium by slight sonication, until a homogeneous dispersion was obtained, and mechanically stirred for $30 \mathrm{~min}$. The sample was again centrifuged (10 min at $1300 \mathrm{rpm}$ ), the supernatant removed and the residue of IONPs redispersed again in $1 \mathrm{~mL}$ of the biological medium. After $4 \mathrm{~h}$ of incubation under mechanical stirring, the IONPs were sedimented by centrifugation (10 $\mathrm{min}$ at 13,000 rpm), the supernatant discarded, and the resulting residue allowed to dry at air prior to the TGA analysis.

\subsubsection{Inductively Coupled Plasma (ICP)}

The Fe content in the samples was determined by inductively coupled plasma-optical emission spectrometry (ICP-OES, PerkinElmer Optima 2100 DV ICP, Waltham, MA, USA) after dissolving the samples in $\mathrm{HNO}_{3}: \mathrm{HCl}$ 1:3 mixtures and diluting them with Millipore water.

\subsubsection{Transmission Electron Microscopy (TEM)}

Particle size and shape were examined by TEM in a JEOL JEM 1010 microscope operating at $100 \mathrm{kV}$. Samples were prepared by placing one drop of a dilute suspension 
onto a carbon-coated copper grid and drying the drop with paper after two minutes. The size distributions were determined through manual analysis of ensembles of over 300 particles found in randomly selected areas of the enlarged micrographs, with Image Tool 3.00 software (UTHSCSA) to obtain the mean size and standard deviation.

\subsubsection{X-ray Powder Diffraction (XRD)}

The $X$-ray powder diffractogram was recorded in the $2 \theta$ range from $0^{\circ}$ to $80^{\circ}$, in a Siemens D-5000 powder diffractometer using $\mathrm{Cu} K \alpha$ radiation $\left(\lambda_{\kappa \alpha}=1.54 \AA\right)$.

\subsubsection{Vibrating Sample Magnetometer (VSM)}

The magnetic characterization was carried out in a vibrating sample magnetometer at room temperature (Lakeshore model 7410, Westerville, $\mathrm{OH}, \mathrm{USA}$ ) by first saturating the sample in a field of $2 \mathrm{~T}$. Saturation magnetization $\left(\mathrm{M}_{\mathrm{S}}\right)$, expressed in emu per $\mathrm{g}$ of $\gamma-\mathrm{Fe}_{2} \mathrm{O}_{3}$ was evaluated by extrapolating the experimental results obtained in the high field range, where the magnetization linearly increases with $1 / \mathrm{H}$, to infinite $\mathrm{H}(1 / \mathrm{H}=0)$.

\subsection{IONPs Internalization by Cells}

\subsubsection{Cell Culture}

U373 glioblastoma cell line was obtained from the American Type Culture Collections (Manassas, VA, USA). The cell line was grown in DMEM supplemented with $10 \%$ of FBS, $2 \mathrm{mM}$ of L-glutamine, $1 \mu \mathrm{g} / \mathrm{mL}$ of fungizone, $100 \mu \mathrm{g} / \mathrm{mL}$ streptomycin and 100 unit of penicillin per $\mathrm{ml}(\mathrm{GIBCO})$. The cell line was maintained at $37^{\circ} \mathrm{C}$ in a humidified atmosphere of $95 \%$ air and $5 \% \mathrm{CO}_{2}$.

\subsubsection{IONPs Sterilization}

To study IONPs uptake by cells, they were sonicated for $5 \mathrm{~min}$ before the incubations. Then, different sterilization procedures were performed: (i) the IONPs were mixed with DMEM (+10\% FBS or without FBS) and filtered with a $0.22 \mu \mathrm{m}$ Millex-GP filter (MerckMillipore Darmstadt, Germany), or (ii) IONPs were sterilized by UV for $1 \mathrm{~h}$ and then mixed with DMEM (+10\% FBS or without FBS).

\subsubsection{IONPs Uptake}

CMI has been used to study the IONPs uptake. First, $5 \times 10^{4}$ glioblastoma cells were plated in tubes of $15 \mathrm{~mL}$ and centrifuged at $1000 \mathrm{rpm}$ for $5 \mathrm{~min}$. Then, the supernatant was removed and $500 \mu \mathrm{L}$ of IONPs solution at 25-125 $\mu \mathrm{g}$ Fe/mL concentration were mixed in DMEM and DMEM with 10\% FBS. Depending on the proportion of FBS supplied to DMEM, $0 \%$ FBS or $10 \%$ FBS, the solution was centrifuged at $1500 \mathrm{rpm}$ for $1 \mathrm{~min}$ or $5 \mathrm{~min}$, respectively. Immediately after, the medium was exchanged with fresh medium and cells were plated in a 24 well plate and maintained at $37^{\circ} \mathrm{C}$ for $24 \mathrm{~h}$.

\subsubsection{Cell Viability}

The cytotoxicity measurements were performed using the Resazurin dye (SigmaAldrich). This assay is used to measure cell viability and proliferation. After CMI method, the medium was replaced with $600 \mathrm{~mL}$ of fresh medium that contained $10 \%$ Resazurin dye. The samples were incubated at $37^{\circ} \mathrm{C}$ for $3 \mathrm{~h}$. Then, the amount of reduced Resazurin was determined by measuring the absorbance of the sample using a UV-visible spectrophotometer (Sinergy H4 microplate reader, Biotek, Winooski, VT, USA) at $570 \mathrm{~nm}$ of wavelength excitation and $600 \mathrm{~nm}$ of emission. For the negative control, $600 \mathrm{~mL}$ of medium with $10 \%$ of Resazurin dye was added to empty wells. After absorbance measurement, the medium was exchanged with fresh medium and the cells were incubated at $37^{\circ} \mathrm{C}$ for $24 \mathrm{~h}$. The viability of the cells was represented as the absorption percentage of treated cells normalized by control cells. All the samples were performed by triplicate. 


\subsubsection{Labelling Efficiency}

The labelling efficiency was calculated by counting the number of Prussian bluestained and unstained labeled cells [26]. Six random optic fields from each sample were taken by light microscope (Leica DMI3000B, Leica Microsystems, Wetzlar, Germany). The estimation of the percentage was determined by the number of blue-stained cells divided by the total cell number per field.

\subsubsection{Scanning Electron Microscopy (SEM)}

SEM images were made in a JEOL, JSM-6400 in order to observe the IONPs distribution on cells. After CMI method, the cells were washed twice with PBS and fixed with $4 \%$ paraformaldehyde and glutaraldehyde solution for $30 \mathrm{~min}$. Then, a dehydration process was performed at different acetone concentrations $(40 \%, 60 \%, 80 \%$ and $100 \%)$ for $5 \mathrm{~min}$. The sample was washed twice for each dehydration step. Finally, the samples were dehydrated using the critical point procedure and coated with gold metal to make their surfaces electrically conductive.

\subsubsection{Intracellular IONPs Quantification after CMI Method}

After the CMI method using $75 \mu \mathrm{g} / \mathrm{mL}$ of initial IONPs, the media was removed and $500 \mu \mathrm{L}$ of fresh DMEM was added. Then, a solution of nitric acid and hydrochloric acid (1:1) was added to the initial volume. The final solution, cells and uptake IONPs, was resuspended and sonicated for $30 \mathrm{~min}$ at $40{ }^{\circ} \mathrm{C}$. After this step, $4 \mathrm{~mL}$ of water MQ was added to achieve the original $5 \mathrm{~mL}$ volume of the CMI method. From this solution, $2.5 \mathrm{~mL}$ was taken and mixed with a solution of Prussian blue, ferrocyanide and hydrochloric acid (1:1). After $15 \mathrm{~min}, 100 \mu \mathrm{L}$ was added to a 96 well-plate (quadruplicate). The absorbance was read at $690 \mathrm{~nm}$ using a Zetasizer Nano ZS device (Malvern Panaytical, Worcestershire, UK). The concentration values were calculated from a calibration curve. This curve was calculated using four different initial concentrations of IONP12 10, 25, 50 and $100 \mu \mathrm{g} / \mathrm{mL}$ and following the same protocol as above.

\subsubsection{MRI Measurements}

After carrying out the CMI method, labeled cells $\left(5 \times 10^{4}\right)$ were fixed with PFA $4 \%$ for $20 \mathrm{~min}$ at room temperature. Afterward, the cells were washed twice with PBS and resuspended in $200 \mu \mathrm{L}$ of $1 \%$ agarose $\left(50^{\circ} \mathrm{C}\right)$ in 96 well plates excluding air bubbles. The samples were then scanned and $T_{1}, T_{2}$, and $T_{2}{ }^{*}$ weighted images were acquired with a Bruker Pharmascan 7 Tesla $(16 \mathrm{~cm})$. From all samples, 1 slice thickness of $1.5 \mathrm{~mm}$ was acquired on coronal orientation (FOV $3 \mathrm{~cm}$ ). For $T_{1}$ maps, RARE (rapid acquisition with relaxation enhancement) sequenced was used with the following parameters, TR: 70-6000 ms, TE: $12.6 \mathrm{~ms}$; average: 1 ; acquisition matrix $128 \times 128\left(234 \mu \mathrm{m}\right.$ spatial resolution). $T_{2}$ maps were based on the acquisition of 50 pondered images on $T_{2}$ by MSME (multi-slice multi-echo) sequence with different eco times. The sequence parameters were the following ones, TR: $5000 \mathrm{~ms}$, TE: $12-600 \mathrm{~ms}, 50$ Ecos number, 1 average, acquisition matrix $128 \times 128$ (234 $\mu \mathrm{m}$ spatial resolution). For $T_{2}{ }^{*}$ maps were obtained 10 pondered images on $T_{2}{ }^{*}$ by MGE (multi-gradient echo) sequence with different eco times and these parameters, TR: $300 \mathrm{~ms}$, TE: 78-40.67 ms, 10 eco numbers, 8 averages, acquisition matrix $256 \times 256(125 \mu \mathrm{m}$ spatial resolution).

\subsection{Statistical Analysis}

The data were analyzed by GraphPad Prism version 6.0. All labelling efficiency samples were compared using a one-way ANOVA indicating significant differences when ${ }^{*} p<0.05,{ }^{* *} p<0.01,{ }^{* * *} p<0.001$. Unless otherwise noted, measurements are reported as the mean \pm standard deviation. 


\section{Results and Discussion}

3.1. Synthesis, Characterization and Colloidal Properties of IONPs with the Same Core and Different Coatings

IONPs with a mean core size of $14.4 \pm 3.7 \mathrm{~nm}$, measured by transmission electron microscopy (TEM) and quasi-spherical shape (see Supporting Information Figure S1A-C) were prepared by the classical Massart's method [35]. An oxidative acid treatment was performed in order to obtain $\gamma-\mathrm{Fe}_{2} \mathrm{O}_{3} \mathrm{NPs}$ (Figure S1D,E) [36,46]. IONPs were named as follows, depending on the coating (Figure 1A): NP (naked), NP-D (dextran), NP-AD (aminodextran), NP-CMD (carboxymethyl-dextran), NP-APS (aminopropyl-trietoxy silane), NPDMSA (dimercaptosuccinic acid). Dextran derivatives are polysaccharides that provide steric stabilization to the inorganic core of the IONPs. In addition, electrostatic stabilization exists also in NP-CMD and NP-AD. By contrast, in the case of NP, NP-DMSA, and NP-APS, there is no steric hindrance protecting the IONPs (or it is negligible) and the stabilization is mainly due to electrostatic repulsion.

A. IONPs coating scheme

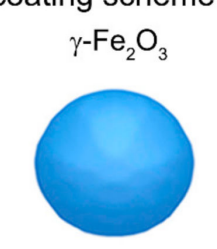

NP-CMD

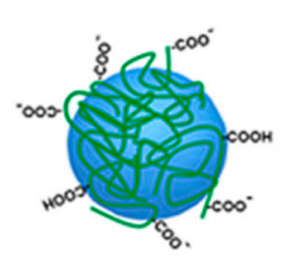

B. Thermogravimetric analysis
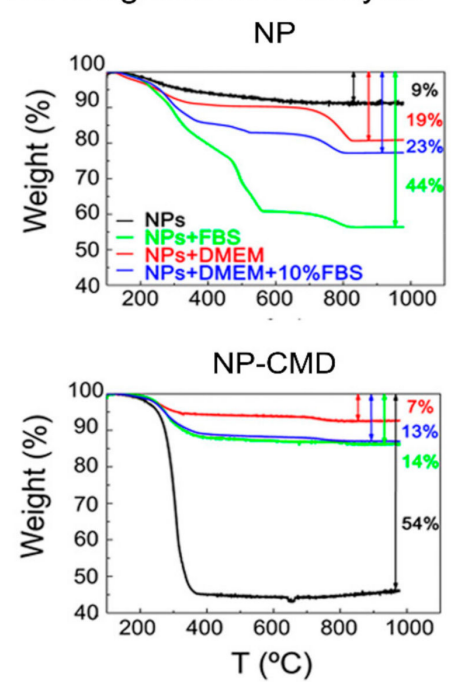

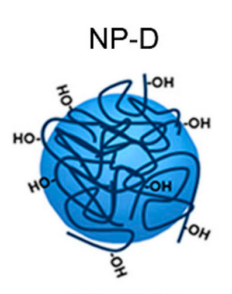

NP-APS

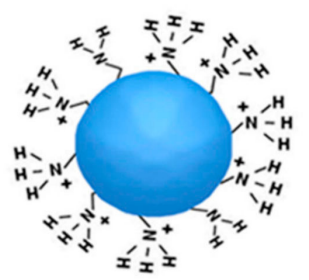

NP-D
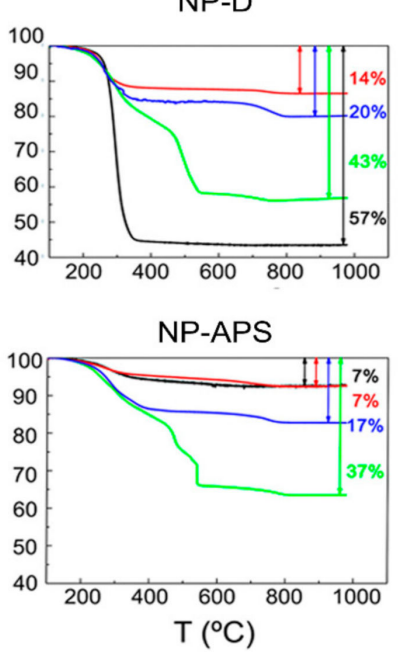

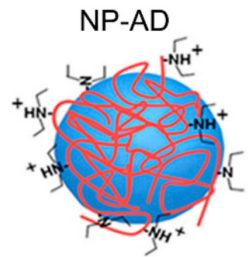

NP-DMSA

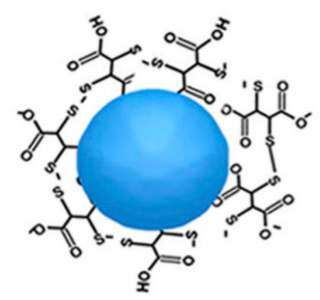

NP-AD
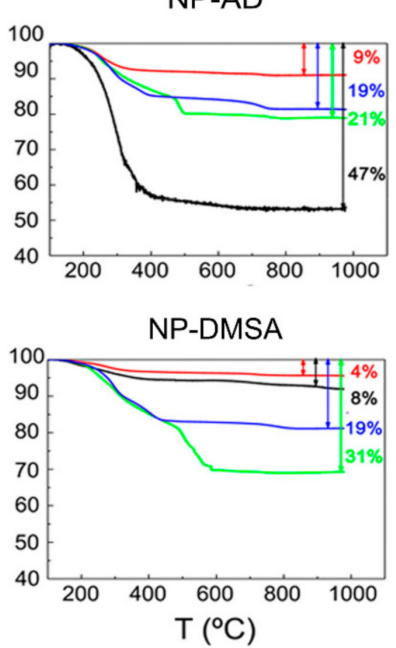

Figure 1. (A) Scheme illustrating the IONPs with the different coatings: NP $\left(\gamma-\mathrm{Fe}_{2} \mathrm{O}_{3}\right), \mathrm{NP}-\mathrm{D}$ (dextran), NP-AD (amino-dextran), NP-CMD (carboxymethyl-dextran), NP-APS (aminopropyltrietoxy silane), NP-DMSA (dimercaptosuccinic acid). (B) TGA measurements of IONPs suspended in different media, water (black), FBS (green), DMEM (red), and DMEM (10\% FBS) (blue). 
When NPs are dispersed in a liquid medium, they frequently undergo aggregation $[47,48]$ as well as adsorption or binding to other solutes present in the medium [49-51]. Via DLS and TGA techniques, aggregation and adsorption processes can be accessed to provide: (i) $D_{\text {hyd }}$ values, obtained by DLS, which are strongly correlated to aggregate sizes; (ii) $\zeta$ potentials, which are related to the contribution of the electrostatic repulsion to the colloidal stability; and (iii) the weight loss, measured by TGA, which yields the amount of organic matter present in the material, i.e., of the coatings and the organic molecules present in culture media such as Dulbecco's modified eagle's medium (DMEM) or fetal bovine serum (FBS). The trend of IONPs aggregation in different media for samples NP, NP-APS, and NP-DMSA, evaluated through their $D_{\text {hyd }}$ values, can be sorted as follows: water < DMEM $(10 \%$ FBS) < DMEM (Table 1). These samples are not stable in DMEM alone, where aggregate sizes larger than $1 \mu \mathrm{m}$ were measured and precipitation of the particles was observed. Besides, very similar aggregate sizes were measured for NP-D and NP-CMD dispersed in the three media and a much higher $D_{h y d}$ value for NP-AD dispersed in DMEM $+10 \%$ FBS than in water or DMEM alone. It is known that the interaction of NPs with proteins can increase the $D_{\text {hyd }}$ either by causing aggregation or by simple adhesion. The later has been purposely employed for engineering NPs and, alone, cannot account for large increases in $D_{\text {hyd }}$ values similar to the ones observed here [52]. On the other hand, aggregation of NPs in protein-rich media has been suggested to rise the local concentration of superparamagnetic IONPs in mesenchymal stem cells. This feature must be controlled or monitored, since it can complicate cell tracking by MRI [53].

Table 1. Mean hydrodynamic diameters (with PDI in parentheses) and zeta potential values of IONPs suspended in water, DMEM cell culture medium and DMEM supplemented with FBS (10\%).

\begin{tabular}{ccccccc}
\hline IONPs & \multicolumn{3}{c}{$\boldsymbol{D}_{\text {hyd }}(\mathbf{n m})$} & \multicolumn{3}{c}{$\zeta$ Potential (mV) } \\
\hline Coating & Water & DMEM & $\begin{array}{c}\text { DMEM } \\
+10 \% \text { FBS }\end{array}$ & Water & DMEM & $\begin{array}{c}\text { DMEM } \\
+10 \% \text { FBS }\end{array}$ \\
& $124(0.1)$ & $1347(0.3)$ & $137(0.2)$ & -8 & -8 & 13 \\
NP & $85(0.2)$ & $132(0.3)$ & $128(0.2)$ & -0.5 & -4 & -6 \\
NP-D & $81(0.2)$ & $76(0.3)$ & $561(0.3)$ & 37 & 10 & -7 \\
NP-AD & $84(0.4)$ & $84(0.1)$ & $79(0.2)$ & -33 & -18 & -18 \\
NP-CMD & $166(0.6)$ & $1342(0.3)$ & $177(0.2)$ & 27 & -6 & -1 \\
NP-APD & $1636(0.2)$ & $335(0.3)$ & -26 & -13 & -12 \\
NP-DMSA & $124(0.1)$ & 1636
\end{tabular}

The $\zeta$ potential values measured in water $(\mathrm{pH}=7.4)$ show that, as expected, NP-APS and NP-AD have high positive charges, NP-DMSA and NP-CMD large negative charges, NP-D is almost neutral, and the uncoated NP has a slightly negative value (Table 1). When IONPs are suspended in DMEM and DMEM + 10\% FBS, NP-DMSA, and NP-CMD shift towards less negative $\zeta$ potential values while the initially positive NP-AD and NPAPS shift to less positive or even negative values. The reduction in $\zeta$ potential values in DMEM can be explained in terms of the interaction of the IONPs' surfaces with the solutes present in the medium (amino acids, vitamins, glucose, and various inorganic ions), which eventually causes the charge shielding [54]. A similar effect over the $\zeta$ potential values can take place when the IONPs are suspended in DMEM + 10\% FBS where IONPs are covered by plasma proteins [49]. NP-protein corona formation is known to produce such a shift of the charges [54], even from positive to negative values [55].

Considering $D_{h y d}$ and $\zeta$ potential values (Table 1 ) it is clear that DMEM causes strong reductions in the $\zeta$ potential values of all charged IONPs, causing aggregation and destabilizing them when they are mainly stabilized by electrostatic repulsion (NP, NP-APS, NP-DMSA) but with no increase of the aggregate size when they are coated with dextran derivatives. Thus, stabilization by steric hindrance is far more efficient than stabilization by electrostatic repulsion. In DMEM supplemented with $10 \%$ of FBS, the $\zeta$ potential values are also affected, but the aggregation of the particles is in general inhibited due to the presence 
of serum proteins in FBS that can adhere to the IONPs surfaces providing a great steric hindrance that stabilizes the particles [40].

To further understand these behaviors, weight losses were measured by TGA on powder samples prepared from the stock water dispersions and also after incubation in DMEM, DMEM $+10 \%$ FBS and FBS. In general, the larger the weight loss, the greater the amount of organic molecules per NP. The trend we observed (DMEM $<$ DMEM $+10 \%$ FBS $\leq$ FBS; see Figure 1B) is coherent with a higher amount of proteins being attached to the IONPs' surfaces as the concentration of proteins in the medium increases. When these results are compared with the TGA performed over samples without incubation in biological media, where only the initial coating accounts for the weight loss, a more complex behavior occurs.

For the naked NP and NP-APS samples, the lowest weight loss is obtained when no incubation has been carried out, as expected, although for NP-APS there is almost no difference between IONPs from the water dispersion and from DMEM incubation. With NP-DMSA the weight loss is slightly higher for IONPs from the water dispersion than after incubation with DMEM, indicating that a partial stripping of the DMSA ligand from the surface caused by the DMEM medium has occurred. In addition, it cannot be discarded that other molecules present in DMEM become attached to the surface of the NPs. This ligand stripping is responsible, together with the electrostatic quenching of the surface charge caused by ions, of the aggregation and destabilization observed in NP, NP-APS, and NP-DMSA (see $D_{\text {hyd }}$ values from Table 1). If DMEM is supplemented with proteins (DMEM $+10 \%$ FBS, FBS), protein adhesion takes place, and the dispersion remains stable in spite of APS or DMSA stripping.

With dextran derivatives, the highest weight loss always occurs by far in the samples without incubation. Thus, the coating is removed to some extent even when it is composed of macromolecules. Despite this, the aggregate size is kept almost unchanged in DMEM, which means that after the partial removal of the coating in NP-D, NP-AD and NP-CMD in that medium, the remaining carbohydrates at the surface are enough to preserve the initial aggregate almost unchanged. Nevertheless, from our results, it is difficult to give a thorough explanation to the fact that the NP-AD has a larger aggregate size in DMEM $+10 \%$ FBS and further investigation would be needed to clarify this point $[56,57]$.

These DLS and TGA results support that IONPs suspended in biological media experience a combination of two processes: (i) removal of the coating (in a greater or lesser extent) and (ii) protein adhesion (protein corona formation). Both of them contribute to the changes commonly observed in surface charge and $D_{\text {hyd }}$ values, including a higher aggregation in DMEM and aggregate stabilization in the presence of proteins. In addition, and importantly, they will influence the interaction of IONPs with the cellular membrane.

\subsection{IONPs Uptake by the CMI Method}

The internalization of IONPs into cells is strongly influenced by their coating and colloidal properties [58], but also by other parameters such as IONPs sterilization and suspension media [41]. In order to evaluate the role of the different coatings, we have used the same IONP core with the above five different coatings to assess their CMI-mediated internalization capabilities. We first resuspended the IONPs in DMEM supplemented with $10 \%$ of FBS and used a filter as the sterilization procedure. Surprisingly, after carrying out the CMI method, we observed from optical microscopy images of Prussian blue staining, that only two types of IONPs' coatings (AD and DMSA) were able to cross the cellular membrane into the cytoplasm (Figure S2A). We speculated that these results might be due to their higher $D_{\text {hyd }}$ (AD: $561 \mathrm{~nm}$; and DMSA: $335 \mathrm{~nm}$ ) compared with the other IONPs.

Accordingly, we tried out different concentrations of FBS ( $0 \%$ and $10 \%)$, which directly influence the $D_{\text {hyd }}$ (Table 1), and should have an impact on the uptake of IONPs by cells, once they reach the values observed for NP-AD and NP-DMSA. Higher speeds and times of incubations can produce additional aggregations and IONPs destabilization when they are under centrifugation forces [59]. Since the elimination of FBS in the media can increase 
the hydrodynamic size of IONPs (Table 1), the centrifugation time was reduced to $1 \mathrm{~min}$, instead of $5 \mathrm{~min}$, to avoid additional IONPs aggregations during CMI but still obtain high labelling efficiency [26]. The CMI method was performed using $1500 \mathrm{rpm}$, where the sedimentation and diffusion forces play an important role without producing any precipitation. Theoretical simulations and our experiments support there is no additional aggregation or IONPs destabilization under the CMI parameters used in this study [27]. Additionally, as filtering may retain part of the IONPs, we changed the sterilization protocol to UV irradiation in order to avoid the loss of IONPs. From Figure S2B, we observed that by simply changing the sterilization protocol we induced IONPs internalization using NP-AD, NP-APS, and NP-DMSA. Therefore, the concentration of FBS and the sterilization protocol altered the CMI-mediated internalization of all types of IONPs assayed, except those coated with CMD (Figure S2C). Depending on CMI parameters, Prussian blue images showed a possible IONPs aggregation on the cellular membrane surface. SEM and transmission electron microscopy (TEM) have been used to deeply understand if the interaction of IONPs with cells is external (aggregates on the surface), internal (IONPs uptake by cells), or both, internal and external interactions $[59,60]$. Previous studies used TEM to corroborate the internalization of IONPs by CMI method [26]. In addition, we observed the formation of agglomerates on top of the cellular membrane by SEM images, that were correlated with higher $D_{\text {hyd }}$, for NP-AD $(561 \mathrm{~nm})$, NP-APS $(1342 \mathrm{~nm})$ and NP-DMSA $(1636 \mathrm{~nm})$ coatings (see SI and Figure S2D). Based on this and previous observations, we fine-tuned the FBS concentration and the type of sterilization protocol until we reached the values that yielded the best performance between CMI-mediated IONPs internalization and avoiding the formation of agglomerates. The best internalization results were obtained when naked NP, NP-D, NP-CMD, and NP-AD were resuspended in DMEM without FBS and using UV as sterilization procedure. Meanwhile, NP-APS (UV sterilization) and NP-DMSA (filtered) were suspended in DMEM with 10\% of FBS (Figure 2A, Table S1).

Interestingly, Prussian blue images show that higher amounts of NP-DMSA and $\mathrm{NP}-\mathrm{AD}$ arrive at the cell membrane and are, therefore, internalized (Figure 2A). The two main features of the IONPs studied here that can influence the variations observed in the internalization are the hydrodynamic diameter (related with the aggregate size) and the $\zeta$ potential. As discussed above, IONPs suspended in DMEM and DMEM $+10 \%$ FBS experience changes in both of them. The aggregate size will predictably be important for the internalization through the CMI method $[26,27]$ and positive $\zeta$ potential values have been reported to enhance it when the classical internalization method by gravity is used [58,61-64]. Our results for CMD- and DMSA-coated NPs support a much higher influence of the aggregate size than of the $\zeta$ potential. Both are negative coatings, but NP-DMSA has a much larger aggregate size $(335 \mathrm{~nm})$ and a much higher labelling efficiency $(98.7 \%)$ than NP-CMD (84 nm and 2.5\%). Indeed, the labelling efficiency of NP-DMSA is similar to the one obtained with NP-AD (97.3\%) and higher than the labelling efficiency with NP-APS (79.5\%), both with positive coatings (Figure 2C). Therefore, we can conclude that when NPs are internalized using the CMI method, the aggregate size is the most critical feature (Table 1). The cell viability was studied by using Resazurin dye. This assay indicates no toxicity in most cases (Figure 2B), although naked NP and NP-AD presented $77 \%$ and $74 \%$ of cell viability, respectively. Probably due to small agglomeration in the case of naked NP or because of the presence of amino dextran groups for the NP-AD [65].

In summary, the suspension media chosen is an important parameter that influences the internalization of IONPs by modifying their colloidal properties. DMEM and DMEM supplemented with FBS cause variation in the hydrodynamic diameters (aggregate sizes) and $\zeta$ potential values affecting the internalization and labelling efficiency of IONPs by the CMI method. It is important to highlight that when trying to maximize the uptake of NPs by cells through the classical internalization method by gravity, the lowest aggregation degree is commonly preferred. However, when the centrifugation mediated internalization method is chosen, our results show that better labelling efficiencies are obtained with larger aggregates (provided that the dispersion is colloidally stable). The highest labelling 
efficiencies were observed for NP-DMSA and NP-AD. The former exhibited no toxicity, but the latter did. Therefore, DMSA coating was chosen to study the influence of core size in cell internalization and MRI contrast enhancement efficiency.

\section{A. Internalized IONPs by the CMI method}

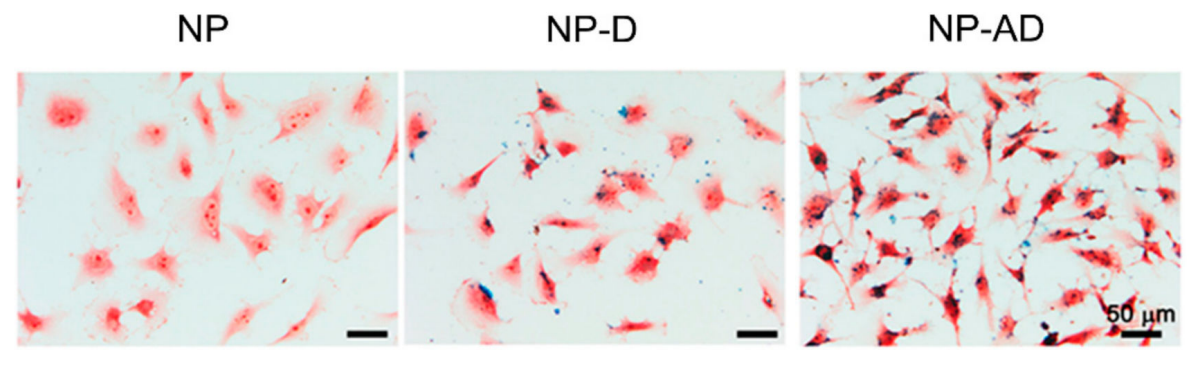

\section{NP-CMD \\ NP-APS \\ NP-DMSA}

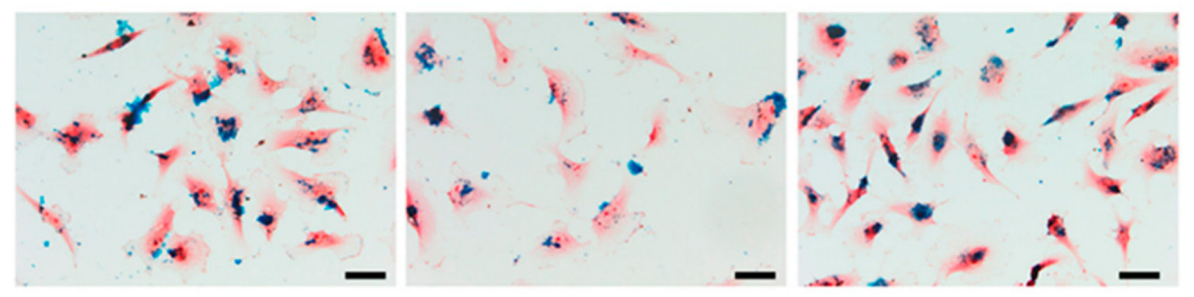

B.

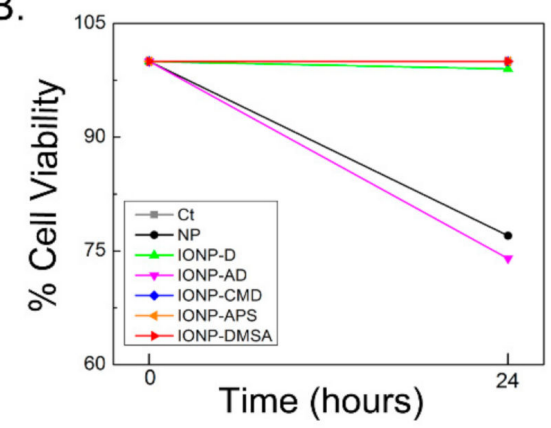

C.

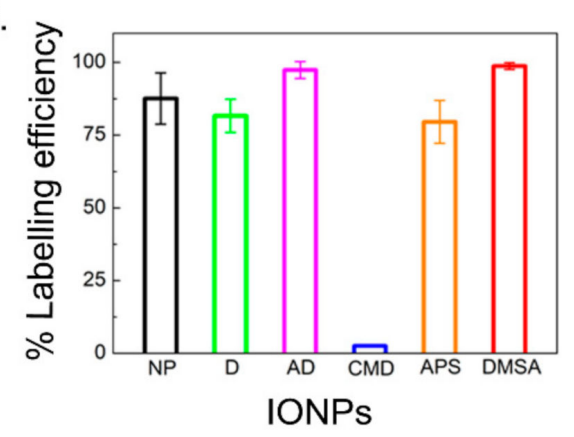

Figure 2. (A) Optical microscopy images of U373 cells after IONPs internalization through the CMI method followed by Prussian blue staining. (B) Cell viability obtained from resazurin assay. (C) IONPs labelling efficiency after CMI. Error bars represent standard deviations.

\subsection{Influence of Core Size on IONPs Uptake by the CMI Method}

After studying the effect of the coating using the same cores, we investigated the effect of the core size using the same coating of DMSA, which offered the best labelling efficiencies with no toxicity. Thus, IONPs with core sizes of 7, 12, 14, 18, 23 and 33 nm were synthesized by thermal decomposition. TEM micrographs with IONPs' size and size distribution are shown in Figure 3A. The magnetic properties of these IONPs were studied by VSM measurements. Figure 3B shows the magnetization of IONPs with different core sizes as a function of the applied magnetic field. All IONPs presented a superparamagnetic behaviour. 
A. Morphology by TEM

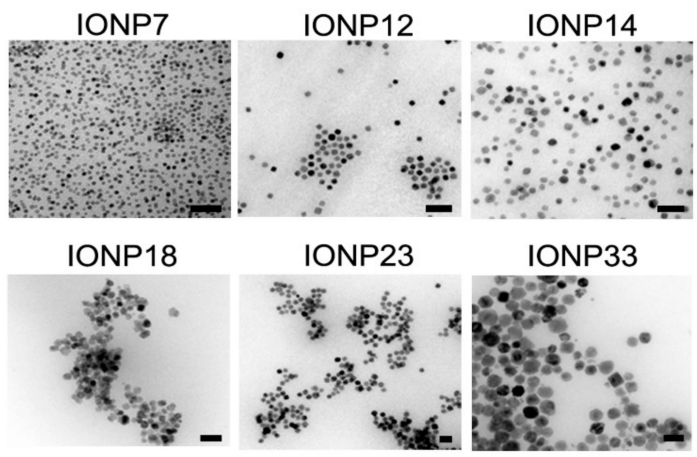

B. Magnetic properties

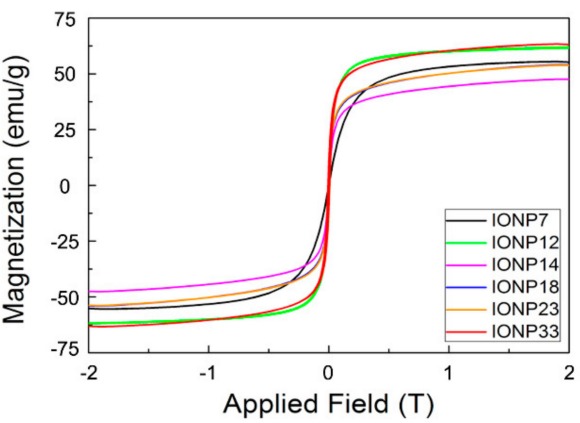

Figure 3. (A) Morphology characterization by TEM and (B) magnetic characterization by VSM of all IONPs with different core sizes. Scale bar: $50 \mathrm{~nm}$.

NPs were then coated with DMSA, through a ligand substitution procedure and the aggregate sizes were evaluated through their hydrodynamic diameters (Table S2). $D_{\text {hyd }}$ in different media follow the trend water $<$ DMEM $+10 \%$ FBS $<$ DMEM. As in the previous examples with different coatings, there is an increase in $D_{\text {hyd }}$ when IONPs are dispersed on DMEM, reaching aggregate sizes at the micron level. Again, the presence of FBS helps to partially stabilize the NPs and the aggregation is limited to sizes in the range 200-500 nm (Table S2). The lowest values of $D_{\text {hyd }}$ are obtained with IONP14 $(212 \mathrm{~nm})$ and IONP18 $(223 \mathrm{~nm})$, clearly differentiated from the rest, which present $D_{h y d} \geq 300 \mathrm{~nm}$. $\zeta$ potential values shift to less negative values the IONPs are dispersed in DMEM or DMEM $+10 \%$ FBS, which is again consistent with the results obtained with the different coatings.

With IONP14 and IONP18 suspended in DMEM 10\% FBS, low internalizations by CMI were observed because of their small $D_{\text {hyd }}$. Therefore, IONP14 and IONP18 were employed in DMEM only, while the remaining IONPs were suspended in DMEM + 10\% FBS. Figure S3 shows the optical images after Prussian blue staining at different initial IONP23 concentrations. Agglomerates appeared on the cell surface concentrations using 100 and $125 \mu \mathrm{g} / \mathrm{mL}$. Therefore, 25, 50 and $75 \mu \mathrm{g} / \mathrm{mL}$ of initial concentration were used to favour internalization. Figure 4A shows optical images of U373 cells incubated with IONPs at different concentrations using the CMI method and after Prussian blue staining. At $25 \mu \mathrm{g} / \mathrm{mL}$, only IONP14 and IONP18 were internalized (Figure 4A) (i). At $50 \mu \mathrm{g} / \mathrm{mL}$, only IONP7 and IONP23 were unable to undergo internalization (Figure 4A) (ii). Finally, at $75 \mu \mathrm{g} / \mathrm{mL}$, IONPs underwent internalization and labelled the cells (Figure 4A) (iii). Resazurin assay indicated no toxicity using any of the IONPs by CMI after $24 \mathrm{~h}$ at an initial concentration of $75 \mu \mathrm{g} / \mathrm{mL}$ (Figure $4 \mathrm{~A}$ ) (iv).

The labelling efficiencies with U373 cells incubated at $75 \mu \mathrm{g} / \mathrm{mL}$ are almost $100 \%$ for all IONPs (Figure 4B). The labelling efficiencies for IONP14 and IONP18 in DMEM with and without FBS have been measured for comparison and to illustrate the influence of the colloidal changes induced by the cell culture media. With both types of IONPs, labelling efficiencies of $\simeq 100 \%$ are reached in DMEM, while in DMEM $+10 \%$ FBS the labelling efficiencies drop dramatically below 70\% (Figure 4B). These data corroborate that higher hydrodynamic diameters could induce an increase in cell labelling using the CMI methodology. 
A. Internalized IONPs by CMI method

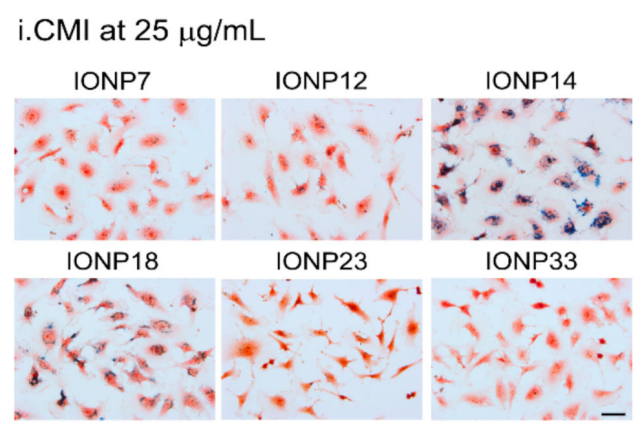

iii.CMI at $75 \mu \mathrm{g} / \mathrm{mL}$

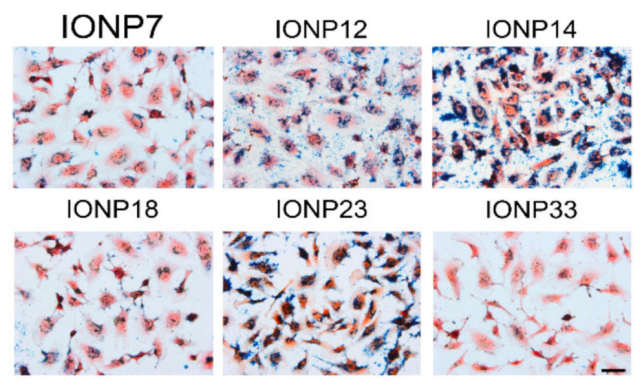

B. Labelling Efficiency

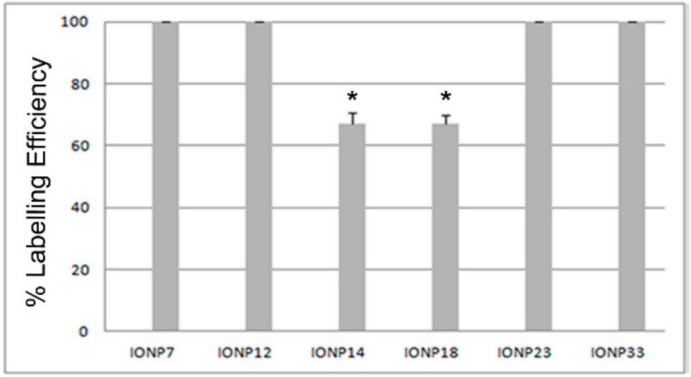

ii.CMI at $50 \mu \mathrm{g} / \mathrm{mL}$

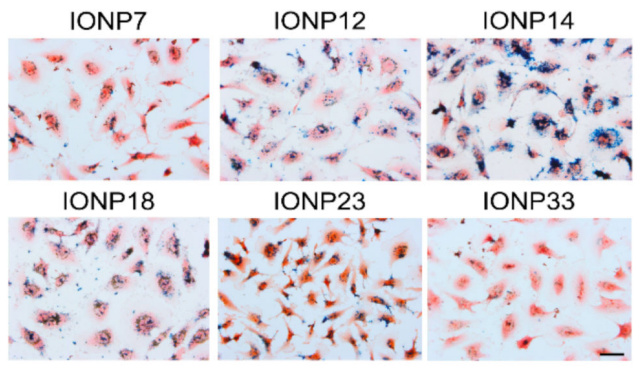

iv.Citotoxicity

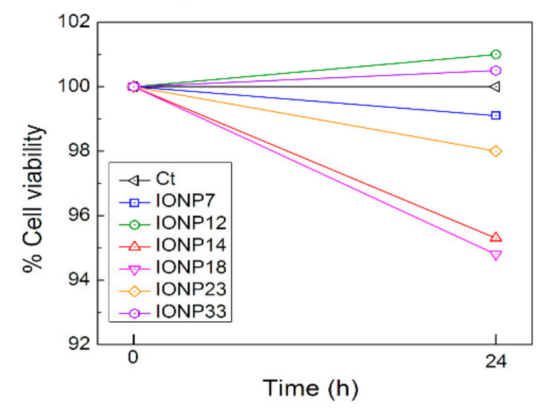

Figure 4. (A) Labelled cells by IONPs using CMI method. Optical images after Prussian blue staining of U373 cell line using different IONPs concentrations of (i) $25 \mu \mathrm{g} / \mathrm{mL}$, (ii) $50 \mu \mathrm{g} / \mathrm{mL}$, and (iii) $75 \mu \mathrm{g} / \mathrm{mL}$ and (iv) cell viability using $75 \mu \mathrm{g} / \mathrm{mL}$ of IONPs incubated after $24 \mathrm{~h}$. (B) IONPs labelling on U373 cells at an initial concentration of $75 \mu \mathrm{g} / \mathrm{mL}$ using DMEM supplemented with $10 \%$ of FBS (left) or without FBS (right). A significant increase in labelling efficiency was obtained when IONPs were suspended in DMEM+0\%FBS compared with DMEM supplemented with $10 \%$ FBS for IONP14 and IONP18.

\subsection{MRI Contrast Enhancement In Vitro}

NPs could be treated as positive or negative contrast agents depending on their particle size, coating and magnetic properties $[30,66]$. Positive contrast agents are made of NPs with small core sizes $(<5 \mathrm{~nm})$, coatings that provide good stability with hydrodynamic sizes between 10-20 nm and paramagnetic properties. These parameters support the $T_{1}$ effect [67]. Since in this study we used superparamagnetic IONPs, with core sizes between 7-23 $\mathrm{nm}$ and higher hydrodynamic sizes, they could be treated as a negative contrast agent which reduces $T_{2}$ signals by shortening the $T_{2}$ relaxation time [30,67]. After incubating the cells with IONPs at concentrations of 25,50 and $75 \mu \mathrm{g} / \mathrm{mL}$, using the CMI method, the relaxation rates $R_{1}, R_{2}$, and $R_{2}{ }^{*}$ were calculated from the measured relaxation times $T_{1}$, $T_{2}$, and $T_{2}{ }^{*}$. These values, together with the $R_{2} / R_{1}$ ratio, are collected in Table 2 . Using a concentration of $75 \mu \mathrm{g} / \mathrm{mL}$, IONP12 and IONP14 developed the higher values of $R_{2}, R_{2}{ }^{*}$ and $R_{2} / R_{1}$ (Figure 5 and Figure $\mathrm{S} 4$ ). 
Table 2. Relaxation rate values, $R_{1}, R_{2}$, and $R_{2}{ }^{*}$ and coefficient $R_{2} / R_{1}$ values from MRI at different IONPs initial concentrations of 25,50 and $75 \mu \mathrm{g} / \mathrm{mL}$.

\begin{tabular}{|c|c|c|c|c|c|}
\hline Samples & $\begin{array}{l}\text { [IONPs] } \\
(\mu \mathrm{g} / \mathrm{mL})\end{array}$ & $R_{1}\left(\mathrm{~s}^{-1}\right)$ & $R_{2}\left(\mathrm{~s}^{-1}\right)$ & $R_{2}^{*}\left(\mathrm{~s}^{-1}\right)$ & $R_{1} / R_{2}$ \\
\hline Control & 50.000 cells & 0.4 & 10.1 & 29.7 & 26.2 \\
\hline \multirow{3}{*}{ IONP7 } & 25 & 0.5 & 8.9 & 16.4 & 17.7 \\
\hline & 50 & 0.4 & 8.8 & 45.9 & 20.4 \\
\hline & 75 & 0.3 & 8.6 & 101.0 & 29.3 \\
\hline \multirow{3}{*}{ IONP12 } & 25 & 0.2 & 7.4 & 35.8 & 32.3 \\
\hline & 50 & 0.5 & 22.8 & 142.3 & 46.4 \\
\hline & 75 & 0.7 & 58.0 & 393.7 & 88.4 \\
\hline \multirow{3}{*}{ IONP14 } & 25 & 0.4 & 13.6 & 103.3 & 33.0 \\
\hline & 50 & 0.4 & 21.9 & 124.8 & 50.5 \\
\hline & 75 & 0.6 & 83.9 & 428.3 & 144.7 \\
\hline \multirow{3}{*}{ IONP18 } & 25 & 0.5 & 11.5 & 34.3 & 22.1 \\
\hline & 50 & 0.5 & 12.7 & 43.9 & 26.6 \\
\hline & 75 & 0.3 & 12.8 & 69.9 & 43.3 \\
\hline \multirow{3}{*}{ IONP23 } & 25 & 0.3 & 10.6 & 42.0 & 31.6 \\
\hline & 50 & 0.4 & 12.6 & 68.2 & 35.2 \\
\hline & 75 & 0.4 & 32.9 & 278.0 & 80.5 \\
\hline \multirow{3}{*}{ IONP33 } & 25 & 0.4 & 9.7 & 72.9 & 23.9 \\
\hline & 50 & 0.4 & 13.2 & 72.5 & 34.2 \\
\hline & 75 & 0.3 & 19.5 & 186.2 & 62.2 \\
\hline
\end{tabular}

Since these IONPs are known as efficient $R_{2}$ or $R_{2}{ }^{*}$ (which takes into account $R_{2}$ and magnetic field inhomogeneities) contrast agents, we are going to focus on these results. Figure 5A shows how $R_{2}{ }^{*}$ values increase with the concentration (of incubation) of all IONPs. At $75 \mu \mathrm{g} / \mathrm{mL}$ it is clear that IONP14 and IONP12 present the topmost $R_{2}{ }^{*}$ values, $428 \mathrm{~s}^{-1}$ and $394 \mathrm{~s}^{-1}$, respectively (Figure 5B and Table 1).

There have been many studies devoted to characterizing the relaxation rates of IONPs $[68,69]$. However, there are fewer examples dealing with relaxation rates of IONPs incubated with cells. For instance, Brisset et al. used 4.7 and $7 \mathrm{~T}$ scanners to study the relaxation rates of two types of IONPs: Ferumoxtran-10 (Sinerem ${ }^{\circledR}$, in the past commercialized as contrast agent by Guerbet) and negatively charged IONPs with a mean core size of $8.7 \mathrm{~nm}$ [70]. With the same field as the one used in our experiments $(7 \mathrm{~T})$, they observed the best internalization and highest contrast in cells $\left(10^{6}\right.$ cells $)$ with the negatively charged IONPs, with $R_{2}{ }^{*}$ values up to $200 \mathrm{~s}^{-1}$ at the highest concentration. That $R_{2}{ }^{*}$ is above the maximum one that we have measured with IONP7 $\left(101 \mathrm{~s}^{-1}\right)$ and well below the measured $R_{2}{ }^{*}$ of IONP12 $\left(394 \mathrm{~s}^{-1}\right)$ and IONP14 $\left(428 \mathrm{~s}^{-1}\right)$. In another work, Zhang et al. studied the relaxation rates of DMSA-coated IONPs functionalized with methotrexate and encapsulated with the hepatitis B virus core antigen using a $7 \mathrm{~T}$ scanner [71]. The core size of these NPs was $(11.7 \pm 1.6) \mathrm{nm}$ and the concentrations used for the incubation with cells were in the range $[\mathrm{Fe}] \simeq 200-3000 \mu \mathrm{g} / \mathrm{mL}$. They tested $10^{7}$ cells and the highest $R_{2}$ value that they observed was $70 \mathrm{~s}^{-1}$, obtained at the highest concentration of $3000 \mu \mathrm{g} / \mathrm{mL}$ IONPs. However, our experiments for IONP14 presented a higher $R_{2}$ value $\left(84 \mathrm{~s}^{-1}\right)$ using a concentration of NPs 40 times lower than in this study. A recent study using IONPs coated with an amino alcohol derivate of glucose reached the highest labelling and intracellular iron content using an initial concentration of $50 \mu \mathrm{g} / \mathrm{mL}$. The $R_{2}$ value from a $7 \mathrm{~T}$ magnetic resonance image was close to $40 \mathrm{~s}^{-1}$ but they also observed a decrease in cellular 
viability using $50 \mu \mathrm{g} / \mathrm{mL}$ and needed to reduce to $37.5 \mu \mathrm{g} / \mathrm{mL}$ for the rest of their study $\left(R_{2} \simeq 20 \mathrm{~s}^{-1}\right)$ [72]. This value was below our best relaxation rate (Table 2$)$ and highlights the efficiency of the internalization of IONPs in cells using the CMI method for excellent labelling and viability.

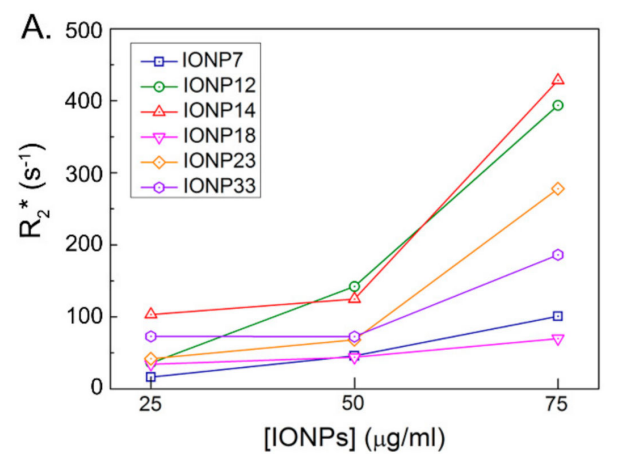

C. Images of IONP14

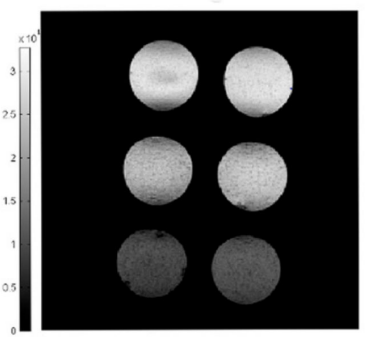

ONP14

$25 \mu \mathrm{g} / \mathrm{mL}$

$50 \mu \mathrm{g} / \mathrm{mL}$

$75 \mu \mathrm{g} / \mathrm{mL}$

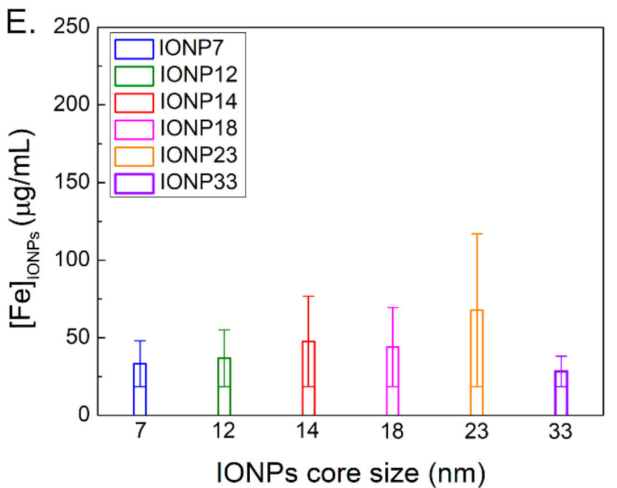

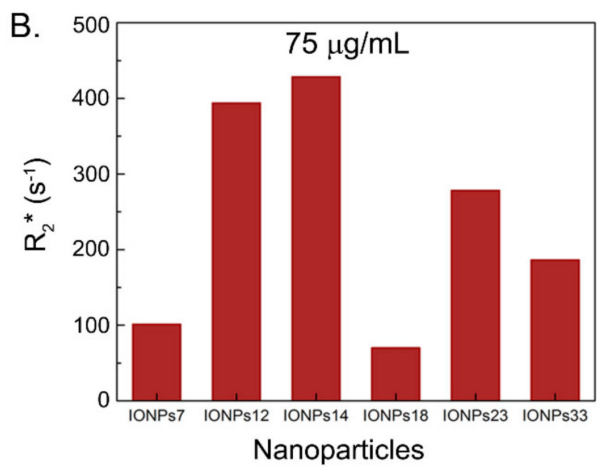

D. MRI at $75 \mu \mathrm{g} / \mathrm{mL}$ of IONPs

Image $\quad$ Maps $\mathrm{T}_{2}{ }^{*}(\mathrm{~ms})$

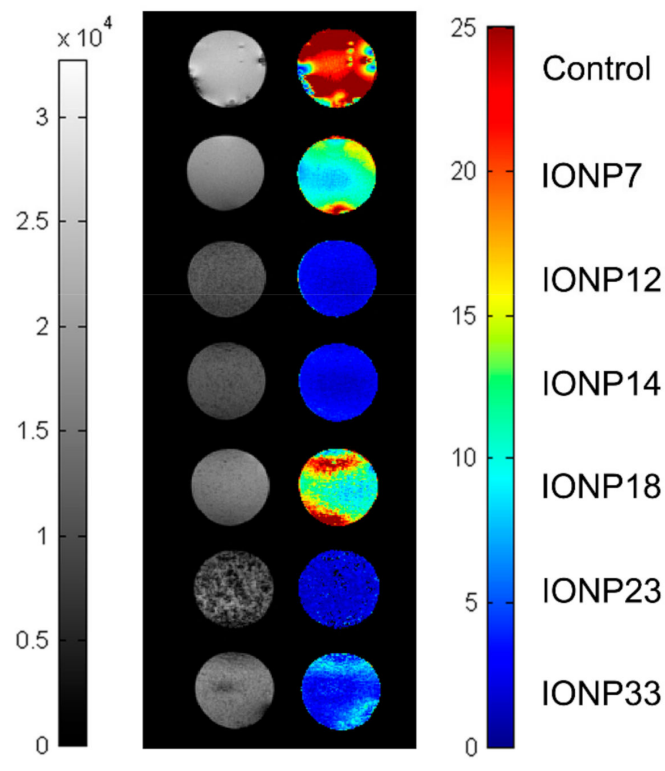

Figure 5. (A) $R_{2}{ }^{*}$ values at three different IONPs concentrations for all the core NPs sizes. (B) $R_{2}{ }^{*}$ values of all IONPs at a concentration of $75 \mu \mathrm{g} / \mathrm{mL}$. See the highest values for IONP14 and IONP12. (C) Duplicate contrast images of all IONPs at an initial concentration of $75 \mu \mathrm{g} / \mathrm{mL}$ of IONP14 show a better contrast when increasing the concentration of IONPs. (D) Contrast and $T_{2}{ }^{*}$ maps of all IONPs at a concentration of $75 \mu \mathrm{g} / \mathrm{mL}$. (E) Intracellular iron concentration after CMI method measured by Prussian blue staining images using $75 \mu \mathrm{g} / \mathrm{mL}$ of IONPs.

Characterizing the colloidal properties of IONPs is relevant for optimizing their performance and $D_{\text {hyd }} \geq 300 \mathrm{~nm}$ are the most appropriate when applying CMI. Using this methodology, we were able to have faster labelling and internalization of IONPs in cells than conventional methods employing gravity [26,27]. We observed that $R_{2}{ }^{*}$ increases while incrementing the core size from 7 to $12 \mathrm{~nm}$, achieving the maximum value for a core of $14 \mathrm{~nm}$. Further pushing those sizes to $18 \mathrm{~nm}, 23 \mathrm{~nm}$ and $33 \mathrm{~nm}$ will produce a decay of the $R_{2}{ }^{*}$ value. The colloidal properties will enhance the labelling of IONPs, but MRI responses have a clear relation with the IONPs core showing excellent results when using $12-14 \mathrm{~nm}$ core sizes. The darker signal due to the IONPs contrast can be appreciated in 
Figure 5C, where darker images are obtained as the concentration of IONP14 increases. In general, IONPs with core sizes of 12 and $14 \mathrm{~nm}$ produce better contrasts on the MRI maps (Figure 5D left) and lower $T_{2}{ }^{*}$ values (Figure 5C right) than IONPs with larger or smaller cores and, therefore, they are more suitable NPs for U373 cell labelling and MRI detection.

To determine if the higher $R_{2}{ }^{*}$ values are due to a higher intracellular iron after CMI method, we calculated the iron concentration after CMI by Prussian blue staining. The highest amount of IONPs inside of the cell was obtained using IONPs with a core size of $23 \mathrm{~nm}$ with $67.8 \mu \mathrm{g} / \mathrm{mL}$ (Figure 5E). The concentration for IONP12 and IONP14 was $36.9 \mu \mathrm{g} / \mathrm{mL}$ and $47.6 \mu \mathrm{g} / \mathrm{mL}$, respectively. The upmost contrast enhancement found by MRI was obtained using IONPs with a $14 \mathrm{~nm}$ of core size, coated with DMSA, at an initial concentration of $75 \mu \mathrm{g} / \mathrm{mL}$. These IONPs provide a new experimental source for MRI in cancer diagnosis. Therefore, the high $T_{2}$ contrast enhancement obtained for both IONPs, IONP12 and IONP14, must be due to a combination of parameters: colloidal properties based on core size and coating and high labelling efficiency using the CMI method. Controlling these NPs synthesis parameters and their uptake methodology will provide the possibility of the modification for future agent labels for improving the relaxation rates for MRI applications.

\section{Conclusions}

The characterization of colloidal properties of IONPs and their interaction with biofluids is important in order to study the labelling ability. In conclusion, we found that IONPs suspended in biological media experience a partial removal of the coating and adhesion of proteins and other molecules. The FBS concentration alters the CMI-mediated internalization of all types of IONPs assayed, except in those coated with CMD. Interestingly, using CMI with IONPs coated with small molecules, as DMSA, the cells present the highest labelling efficiency. The difference in the core size did not change the colloidal properties for CMI methodology. Using an initial concentration of $75 \mu \mathrm{g} / \mathrm{mL}$ of IONPs with a core size of $14 \mathrm{~nm}$ and coated with DMSA we obtained the highest relaxation rate $R_{2}{ }^{*}, 422 \mathrm{~s}^{-1}$ and a coefficient $R_{2} / R_{1}$ of 144.7 by MRI measurements. These results showed that a good contrast will require using a core size range between $12-14 \mathrm{~nm}$ coated with DMSA in order to achieve selected colloidal properties to obtain greater labelling via the CMI methodology. Moreover, these results are in good agreement with the in-silico predictions of our previous work [27], where IONPs with DMSA exhibited strong flux changes towards cells in very short times when CMI was employed. This study opens the opportunity to use this new NP-based technology for improving the contrast in MRI. It will also be useful in other biomedical applications that need improvements in labelling cells for treatments in different diseases as cancer or in the regenerative medicine field.

Supplementary Materials: The following are available online at https:/ /www.mdpi.com/article/ 10.3390/nano11112888/s1, Figure S1: (A-C) Selected TEM micrographs and histogram showing the size distribution of IONPs. (D) XRD pattern and diffraction maxima from maghemite nanoparticles. (E) VSM measurements for the different coated IONPs. Key words: NP (naked), NP-D (dextran), NP-AD (amino-dextran), NP-CMD (carboxymethyl-dextran), NP-APS (aminopropyl-trietoxy silane), and NP-DMSA (dimercaptosuccinic acid). Figure S2: Optical microscopy images of U373 cells after Prussian blue staining following: (A) filtered IONPs suspended in DMEM with 10\% FBS, (B) unfiltered IONPs suspended in DMEM with 10\% of FBS, and (C) un-filtered IONPs in DMEM at $0 \%$ of FBS. (D) Scanning electron microscopy of a control U373 cells, filtered NP-AD on DMEM 10\% FBS, un-filtered NP-APS and NP-DMS on DMEM $0 \%$ FBS. White arrows show IONPs on the cell membrane surface. Scale bars: black $=50 \mu \mathrm{m}$, white $=25 \mu \mathrm{m}$. Table S1: Colloidal properties of IONPs from Table 1, after CMI improvements. Table S2: Mean hydrodynamic diameters (with PDI in parentheses) and zeta potential values of IONPs with different size core suspended in water, DMEM cell culture medium and DMEM supplemented with FBS (10\%). Figure S3: Prussian blue optical images of IONP23 on U373 cells at different concentrations, 25, 50, 75, 100 and $125 \mu \mathrm{g} / \mathrm{mL}$. Scale bar: $50 \mu \mathrm{m}$. Figure S4: contrast images and maps of (A) $T_{1}$, (B) $T_{2}$ at an initial concentration of $25 \mu \mathrm{g} / \mathrm{mL}, 50 \mu \mathrm{g} / \mathrm{mL}$ and $75 \mu \mathrm{g} / \mathrm{mL}$ for all IONPs. (C) (left) $R_{1}$ (up) and $R_{2}$ (down) values for all 
IONPs at different concentrations. (C) (right) values of $R_{1}$ (up) and $R_{2}$ (down) using $75 \mu \mathrm{g} / \mathrm{mL}$ for all IONPs. (D) Contrast and maps of $T_{2}{ }^{*}$ of all IONPs using $25 \mu \mathrm{g} / \mathrm{mL}, 50 \mu \mathrm{g} / \mathrm{mL}$ and $75 \mu \mathrm{g} / \mathrm{mL}$ initial concentration.

Author Contributions: Conceptualization, S.M.O., G.S., Á.A.-S.; methodology, B.C.-L., S.M.O., L.d.1.C.; validation, B.C.-L., S.M.O.; formal analysis, B.C.-L., S.M.O., L.d.l.C.; investigation, B.C.-L., S.M.O., L.d.1.C., G.S., Á.A.-S.; resources, G.S., Á.A.-S.; writing-original draft preparation, B.C.-L., G.S., Á.A.-S.; writing—review and editing, B.C.-L., S.M.O., L.d.l.C., G.F.C., J.B.-B., L.P., G.S., Á.A.-S.; supervision, S.M.O., G.S., Á.A.-S.; project administration, B.C.-L., S.M.O., G.S., Á.A.-S.; funding acquisition, G.S., Á.A.-S., G.F.C., J.B.-B. All authors have read and agreed to the published version of the manuscript.

Funding: This work was supported by Fondo de Investigaciones Sanitarias, FIS [PI17/01489] and the Miguel Servet Program [CP11/00147 and CPII16/00056] from Instituto de Salud Carlos III (AAS); RTC-2015-3846-1 (AAS) and RTC-2016-4990-1 (AAS) from Spanish Ministerio de Economía y Competitividad (MINECO)/FEDER funds. GS gratefully acknowledges projects PID2019-106301RB-I00 from Spanish Ministry of Science, Innovation and Universities and NANOMAGCOST-CM, P2018/NMT4321 from Madrid Regional Government. BCL acknowledges MINECO (FPI program fellowship) from Spain. GFC thanks the funding from Ministerio de Ciencia e Innovación, Spain (Grant Number PID2019-110895RB-I00). This research has also been supported by a grant awarded to GFC and JBB by the Junta de Comunidades de Castilla-La Mancha, Spain (Grant Number SBPLY/19/180501/000211). GFC and JBB also thank funding from project supported by the James S. Mc. Donnell Foundation 21st Century Science Initiative in Mathematical and Complex Systems Approaches for Brain Cancer (USA) [Collaborative Award 220020560].

Conflicts of Interest: The authors declare no conflict of interest.

\section{References}

1. Weissleder, R.; Nahrendorf, M.; Pittet, M.J. Imaging Macrophages with Nanoparticles. Nat. Mater. 2014, 13, 125-138. [CrossRef] [PubMed]

2. Gao, Y.; Lim, J.; Teoh, S.-H.; Xu, C. Emerging Translational Research on Magnetic Nanoparticles for Regenerative Medicine. Chem. Soc. Rev. 2015, 44, 6306-6329. [CrossRef] [PubMed]

3. Mosayebi, J.; Kiyasatfar, M.; Laurent, S. Synthesis, Functionalization, and Design of Magnetic Nanoparticles for Theranostic Applications. Adv. Healthc. Mater. 2017, 6, 1700306. [CrossRef] [PubMed]

4. Israel, L.L.; Galstyan, A.; Holler, E.; Ljubimova, J.Y. Magnetic Iron Oxide Nanoparticles for Imaging, Targeting and Treatment of Primary and Metastatic Tumors of the Brain. J. Control. Release 2020, 320, 45-62. [CrossRef]

5. Tang, T.; Valenzuela, A.; Petit, F.; Chow, S.; Leung, K.; Gorin, F.; Louie, A.Y.; Dhenain, M. In Vivo MRI of Functionalized Iron Oxide Nanoparticles for Brain Inflammation. Contrast Media Mol. Imaging 2018, 2018, 3476476. [CrossRef]

6. Johannsen, M.; Gneveckow, U.; Taymoorian, K.; Thiesen, B.; Waldöfner, N.; Scholz, R.; Jung, K.; Jordan, A.; Wust, P.; Loening, S.A. Morbidity and Quality of Life during Thermotherapy Using Magnetic Nanoparticles in Locally Recurrent Prostate Cancer: Results of a Prospective Phase I Trial. Int. J. Hyperth. 2007, 23, 315-323. [CrossRef]

7. Maier-Hauff, K.; Ulrich, F.; Nestler, D.; Niehoff, H.; Wust, P.; Thiesen, B.; Orawa, H.; Budach, V.; Jordan, A. Efficacy and Safety of Intratumoral Thermotherapy Using Magnetic Iron-Oxide Nanoparticles Combined with External Beam Radiotherapy on Patients with Recurrent Glioblastoma Multiforme. J. Neurooncol. 2011, 103, 317-324. [CrossRef]

8. Smith, B.R.; Gambhir, S.S. Nanomaterials for In Vivo Imaging. Chem. Rev. 2017, 117, 901-986. [CrossRef]

9. M.D. Anderson Cancer Center. Pilot Feasibility Study of Iron Oxide Nanoparticle Magnetic Resonance Dynamic Contrast Enhanced MRI for Primary and Nodal Tumor Imaging in Locally Advanced Head and Neck Squamous Cell Carcinomas; Clinicaltrials.Gov Identifier: NCT01895829. 2021. Available online: https:/ / clinicaltrials.gov/ct2/history/NCT01895829?V_15 =View (accessed on 21 October 2021).

10. Second Affiliated Hospital, School of Medicine, Zhejiang University. A Phase I Clinical Trial of Neoadjuvant Chemotherapy With/Without Superparamagnetic Iron Oxide Nanoparticles and Spinning Magnetic Field for Patients with Osteosarcoma; Clinicaltrials.Gov Identifier: NCT04316091. 2020. Available online: https://clinicaltrials.gov/ct2/show/NCT04316091 (accessed on 21 October 2021).

11. Radboud University. Preoperative Detection of Lymph Node Metastases in Pancreatic and Periampullary Carcinoma Using Ultrasmall Super Paramagnetic Iron Oxide Nanoparticle Ferumoxtran-10; Clinicaltrials.Gov Identifier: NCT04311047. 2021. Available online: https:/ / clinicaltrials.gov/ct2/show / NCT04311047 (accessed on 21 October 2021).

12. MegaPro Biomedical Co. Ltd. A Phase I Study to Determine the MTD and to Evaluate Pharmacokinetic, Safety/Tolerability, and Efficacy Profiles of IOP Injection for MRI Contrast Agent in Healthy Subjects; Clinicaltrials.Gov Identifier: NCT02744248. 2018. Available online: https:/ / clinicaltrials.gov/ct2/show /NCT02744248 (accessed on 21 October 2021). 
13. Neuwelt, E. Pilot Study to Compare Dynamic MR Imaging Changes in Patients with Recurrent High Grade Glioma, Receiving an Antiangiogenic Drug, Bevacizumab, versus Dexamethasone. Dual Agent MR Imaging Study, Using Gadolinium and Ferumoxytol (Code 7228); Clinicaltrials.Gov Identifier: NCT00769093. 2017. Available online: https:/ /clinicaltrials.gov/ct2/show /NCT00769 093 (accessed on 21 October 2021).

14. Mukesh Harisinghani, MD, Principal Investigator, Massachusetts General Hospital. Pre-Operative Nodal Staging of Thyroid Cancer Using Ultra-Small Superparamagnetic Iron Oxide Magnetic Resonance Imaging (USPIO MRI): Preliminary Study; Clinicaltrials.Gov Identifier: NCT01927887. 2017. Available online: https:/ / clinicaltrials.gov/ct2/show/NCT01927887 (accessed on 21 October 2021).

15. M.D. Anderson Cancer Center. Clinical and Technical Feasibility of a Ultrasuperparamagnetic Nanoparticle Iron Oxide (USPIO)Enhanced Magnetic Resonance Lymph Node Imaging; Clinicaltrials.Gov Identifier: NCT01815333. 2020. Available online: https: / / clinicaltrials.gov / ct2/show / NCT01815333 (accessed on 21 October 2021).

16. Ralph, W.M.D. Improved Pre-Operative Staging of Pancreatic Cancer Using Superparamagnetic Iron Oxide Magnetic Resonance Imaging (SPIO MRI); Clinicaltrials.Gov Identifier: NCT00920023. 2017. Available online: https://clinicaltrials.gov/ct2/show / NCT00920023 (accessed on 21 October 2021).

17. Zeineh, M. 7T MRI Ferumoxytol-Enhanced Characterization of Multiple Sclerosis and Demyelinating Diseases; Clinicaltrials.Gov Identifier: NCT01973517. 2018. Available online: https:/ / clinicaltrials.gov/ct2/show / NCT01973517 (accessed on 21 October 2021).

18. National Institute of Neurological Disorders and Stroke (NINDS). In Vivo Characterization of Inflammation With Ferumoxytol, an Ultrasmall Superparamagnetic Iron Oxide Nanoparticle, on 7 Tesla Magnetic Resonance Imaging; Clinicaltrials.Gov Identifier: NCT02511028. 2021. Available online: https:/ / clinicaltrials.gov/ct2/show/NCT02511028 (accessed on 21 October 2021).

19. University of Edinburgh. Ferumoxytol for Magnetic Resonance Imaging of Myocardial Infarction; Clinicaltrials.Gov Identifier: NCT01323296. 2014. Available online: https:/ / clinicaltrials.gov/ct2/show / NCT01323296 (accessed on 21 October 2021).

20. University of Edinburgh. Assessment of Cellular Inflammation Following Acute Myocardial Infarction Application of Ultrasmall Superparamagnetic Particles Of Iron Oxide; Clinicaltrials.Gov Identifier: NCT01995799. 2013. Available online: https:// clinicaltrials.gov/ct2/show / NCT01995799 (accessed on 21 October 2021).

21. Khan, S. Investigation of Vascular Inflammation in Migraine without Aura Using Molecular Nano-Imaging and Black Blood Imaging MRI; Clinicaltrials.Gov Identifier: NCT02549898. 2018. Available online: https:/ / clinicaltrials.gov/ct2/show /NCT025 49898 (accessed on 21 October 2021).

22. University of Edinburgh. Inflammatory Cell Labelling and Tracking with Magnetic Resonance Imaging after Myocardial Infarction; Clinicaltrials.Gov Identifier: NCT01127113. 2014. Available online: https:/ clinicaltrials.gov/ct2/show / NCT01127113 (accessed on 21 October 2021).

23. Ali, A.A.A.; Shahror, R.A.; Chen, K.-Y. Efficient Labeling Of Mesenchymal Stem Cells For High Sensitivity Long-Term MRI Monitoring In Live Mice Brains. Int. J. Nanomed. 2020, 15, 97-114. [CrossRef]

24. Ni, J.-S.; Li, Y.; Yue, W.; Liu, B.; Li, K. Nanoparticle-Based Cell Trackers for Biomedical Applications. Theranostics 2020, 10, 1923-1947. [CrossRef]

25. Estelrich, J.; Sánchez-Martín, M.J.; Busquets, M.A. Nanoparticles in Magnetic Resonance Imaging: From Simple to Dual Contrast Agents. Int. J. Nanomed. 2015, 10, 1727-1741.

26. Ocampo, S.M.; Rodriguez, V.; de la Cueva, L.; Salas, G.; Carrascosa, J.L.; Josefa Rodríguez, M.; García-Romero, N.; Cuñado, J.L.F.; Camarero, J.; Miranda, R.; et al. G-Force Induced Giant Efficiency of Nanoparticles Internalization into Living Cells. Sci. Rep. 2015, 5, 15160. [CrossRef] [PubMed]

27. Calvo, G.F.; Cortés-Llanos, B.; Belmonte-Beitia, J.; Salas, G.; Ayuso-Sacido, Á. Modelling the Role of Flux Density and Coating on Nanoparticle Internalization by Tumor Cells under Centrifugation. Appl. Math. Model. 2020, 78, 98-116. [CrossRef]

28. Markides, H.; Rotherham, M.; El Haj, A.J. Biocompatibility and Toxicity of Magnetic Nanoparticles in Regenerative Medicine. J. Nanomater. 2012, 2012, e614094. [CrossRef]

29. Nosrati, H.; Salehiabar, M.; Fridoni, M.; Abdollahifar, M.-A.; Kheiri Manjili, H.; Davaran, S.; Danafar, H. New Insight about Biocompatibility and Biodegradability of Iron Oxide Magnetic Nanoparticles: Stereological and In Vivo MRI Monitor. Sci. Rep. 2019, 9, 7173. [CrossRef]

30. Corot, C.; Warlin, D. Superparamagnetic Iron Oxide Nanoparticles for MRI: Contrast Media Pharmaceutical Company R\&D Perspective. Wiley Interdiscip. Rev. Nanomed. Nanobiotechnol. 2013, 5, 411-422. [PubMed]

31. Lartigue, L.; Innocenti, C.; Kalaivani, T.; Awwad, A.; del Sanchez Duque, M.M.; Guari, Y.; Larionova, J.; Guérin, C.; Montero, J.L.G.; Barragan-Montero, V.; et al. Water-Dispersible Sugar-Coated Iron Oxide Nanoparticles. An Evaluation of Their Relaxometric and Magnetic Hyperthermia Properties. J. Am. Chem. Soc. 2011, 133, 10459-10472. [CrossRef]

32. Pothayee, N.; Balasubramaniam, S.; Pothayee, N.; Jain, N.; Hu, N.; Lin, Y.; Davis, R.M.; Sriranganathan, N.; Koretsky, A.P.; Riffle, J.S. Magnetic Nanoclusters with Hydrophilic Spacing for Dual Drug Delivery and Sensitive Magnetic Resonance Imaging. J. Mater. Chem. B 2013, 1, 1142-1149. [CrossRef]

33. Gutiérrez, L.; de la Cueva, L.; Moros, M.; Mazarío, E.; de Bernardo, S.; de la Fuente, J.M.; Morales, M.P.; Salas, G. Aggregation Effects on the Magnetic Properties of Iron Oxide Colloids. Nanotechnology 2019, 30, 112001. [CrossRef]

34. Fleischer, C.C.; Payne, C.K. Nanoparticle-Cell Interactions: Molecular Structure of the Protein Corona and Cellular Outcomes. Acc. Chem Res. 2014, 47, 2651-2659. [CrossRef] 
35. Massart, R. Preparation of Aqueous Magnetic Liquids in Alkaline and Acidic Media. IEEE Trans. Magn. 1981, 17, 1247-1248. [CrossRef]

36. Costo, R.; Bello, V.; Robic, C.; Port, M.; Marco, J.F.; Puerto Morales, M.; Veintemillas-Verdaguer, S. Ultrasmall Iron Oxide Nanoparticles for Biomedical Applications: Improving the Colloidal and Magnetic Properties. Langmuir 2012, 28, 178-185. [CrossRef]

37. Safi, M.; Courtois, J.; Seigneuret, M.; Conjeaud, H.; Berret, J.-F. The Effects of Aggregation and Protein Corona on the Cellular Internalization of Iron Oxide Nanoparticles. Biomaterials 2011, 32, 9353-9363. [CrossRef] [PubMed]

38. Bautista, M.C.; Bomati-Miguel, O.; del Morales, M.P.; Serna, C.J.; Veintemillas-Verdaguer, S. Surface Characterisation of DextranCoated Iron Oxide Nanoparticles Prepared by Laser Pyrolysis and Coprecipitation. J. Magn. Magn. Mater. 2005, $293,20-27$. [CrossRef]

39. Chamorro, S.; Gutierrez, L.; Vaquero, M.P.; Verdoy, D.; Salas, G.; Luengo, Y.; Brenes, A.; Teran, F.J. Safety Assessment of Chronic Oral Exposure to Iron Oxide Nanoparticles. Nanotechnology 2015, 26, 205101. [CrossRef]

40. Dutz, S.; Clement, J.H.; Eberbeck, D.; Gelbrich, T.; Hergt, R.; Muller, R.; Wotschadlo, J.; Zeisberger, M. Ferrofluids of Magnetic Multicore Nanoparticles for Biomedical Applications. J. Magn. Magn. Mater. 2009, 321, 1501-1504. [CrossRef]

41. Luengo, Y.; Nardecchia, S.; Morales, M.P.; Serrano, M.C. Different Cell Responses Induced by Exposure to Maghemite Nanoparticles. Nanoscale 2013, 5, 11428-11437. [CrossRef]

42. Park, J.; An, K.; Hwang, Y.; Park, J.-G.; Noh, H.-J.; Kim, J.-Y.; Park, J.-H.; Hwang, N.-M.; Hyeon, T. Ultra-Large-Scale Syntheses of Monodisperse Nanocrystals. Nat. Mater. 2004, 3, 891-895. [CrossRef]

43. Sun, S.; Zeng, H.; Robinson, D.B.; Raoux, S.; Rice, P.M.; Wang, S.X.; Li, G. Monodisperse MFe2O4 (M = Fe, Co, Mn) Nanoparticles. J. Am. Chem. Soc. 2004, 126, 273-279. [CrossRef]

44. Salas, G.; Casado, C.; Teran, F.J.; Miranda, R.; Serna, C.J.; Morales, M.P. Controlled Synthesis of Uniform Magnetite Nanocrystals with High-Quality Properties for Biomedical Applications. J. Mater. Chem. 2012, 22, 21065-21075. [CrossRef]

45. Pacakova, B.; Kubickova, S.; Salas, G.; Mantlikova, A.R.; Marciello, M.; Morales, M.P.; Niznansky, D.; Vejpravova, J. The Internal Structure of Magnetic Nanoparticles Determines the Magnetic Response. Nanoscale 2017, 9, 5129-5140. [CrossRef] [PubMed]

46. Bee, A.; Massart, R.; Neveu, S. Synthesis of Very Fine Maghemite Particles. J. Magn. Magn. Mater. 1995, 149, 6-9. [CrossRef]

47. Moore, T.L.; Rodriguez-Lorenzo, L.; Hirsch, V.; Balog, S.; Urban, D.; Jud, C.; Rothen-Rutishauser, B.; Lattuada, M.; Petri-Fink, A. Nanoparticle Colloidal Stability in Cell Culture Media and Impact on Cellular Interactions. Chem. Soc. Rev. 2015, 44, 6287-6305. [CrossRef] [PubMed]

48. Russel, W.B.; Saville, D.A.; Schowalter, W.R. Colloidal Dispersions; Cambridge University Press: Cambridge, UK, 1989.

49. Mahmoudi, M.; Lynch, I.; Ejtehadi, M.R.; Monopoli, M.P.; Bombelli, F.B.; Laurent, S. Protein Nanoparticle Interactions: Opportunities and Challenges. Chem. Rev. 2011, 111, 5610-5637. [CrossRef]

50. Monopoli, M.P.; AAberg, C.; Salvati, A.; Dawson, K.A. Biomolecular Coronas Provide the Biological Identity of Nanosized Materials. Nat. Nanotechnol. 2012, 7, 779-786. [CrossRef] [PubMed]

51. Lundqvist, M.; Stigler, J.; Elia, G.; Lynch, I.; Cedervall, T.; Dawson, K.A. Nanoparticle Size and Surface Properties Determine the Protein Corona with Possible Implications for Biological Impacts. Proc. Natl. Acad. Sci. USA 2008, 105, 14265-14270. [CrossRef] [PubMed]

52. Yu, S.; Perálvarez-Marín, A.; Minelli, C.; Faraudo, J.; Roig, A.; Laromaine, A. Albumin-Coated SPIONs: An Experimental and Theoretical Evaluation of Protein Conformation, Binding Affinity and Competition with Serum Proteins. Nanoscale 2016, 8 , 14393-14405. [CrossRef]

53. Guldris, N.; Argibay, B.; Gallo, J.; Iglesias-Rey, R.; Carbó-Argibay, E.; Kolen'ko, Y.V.; Campos, F.; Sobrino, T.; Salonen, L.M.; Bañobre-López, M.; et al. Magnetite Nanoparticles for Stem Cell Labeling with High Efficiency and Long-Term in Vivo Tracking. Bioconjugate Chem. 2017, 28, 362-370. [CrossRef]

54. Sabuncu, A.C.; Grubbs, J.; Qian, S.; Abdel-Fattah, T.M.; Stacey, M.W.; Beskok, A. Probing Nanoparticle Interactions in Cell Culture Media. Colloids Surf. B Biointerfaces 2012, 95, 96-102. [CrossRef] [PubMed]

55. Ehrenberg, M.S.; Friedman, A.E.; Finkelstein, J.N.; Oberdörster, G.; McGrath, J.L. The Influence of Protein Adsorption on Nanoparticle Association with Cultured Endothelial Cells. Biomaterials 2009, 30, 603-610. [CrossRef] [PubMed]

56. Gage, S.H.; Stein, B.D.; Nikoshvili, L.Z.; Matveeva, V.G.; Sulman, M.G.; Sulman, E.M.; Morgan, D.G.; Yuzik-Klimova, E.Y.; Mahmoud, W.E.; Bronstein, L.M. Functionalization of Monodisperse Iron Oxide NPs and Their Properties as Magnetically Recoverable Catalysts. Langmuir 2012, 29, 466-473. [CrossRef] [PubMed]

57. Cheon, J.; Kang, N.-J.; Lee, S.-M.; Lee, J.-H.; Yoon, J.-H.; Oh, S.J. Shape Evolution of Single-Crystalline Iron Oxide Nanocrystals. J. Am. Chem. Soc. 2004, 126, 1950-1951. [CrossRef] [PubMed]

58. Saei, A.A.; Yazdani, M.; Lohse, S.E.; Bakhtiary, Z.; Serpooshan, V.; Ghavami, M.; Asadian, M.; Mashaghi, S.; Dreaden, E.C.; Mashaghi, A.; et al. Nanoparticle Surface Functionality Dictates Cellular and Systemic Toxicity. Chem. Mater. 2017, 29, 6578-6595. [CrossRef]

59. Sousa, C.; Sequeira, D.; Kolen'ko, Y.V.; Pinto, I.M.; Petrovykh, D.Y. Analytical Protocols for Separation and Electron Microscopy of Nanoparticles Interacting with Bacterial Cells. Anal. Chem. 2015, 87, 4641-4648. [CrossRef] [PubMed]

60. Vilas-Boas, V.; Espiña, B.; Kolen'ko, Y.V.; Bañobre-Lopez, M.; Duarte, J.A.; Martins, V.C.; Petrovykh, D.Y.; Freitas, P.P.; Carvalho, F.D. Combining CXCR4-Targeted and Nontargeted Nanoparticles for Effective Unassisted in Vitro Magnetic Hyperthermia. Biointerphases 2018, 13, 011005. [CrossRef] [PubMed] 
61. Villanueva, A.; Cañete, M.; Roca, A.G.; Calero, M.; Veintemillas-Verdaguer, S.; Serna, C.J.; del Morales, M.P.; Miranda, R. The Influence of Surface Functionalization on the Enhanced Internalization of Magnetic Nanoparticles in Cancer Cells. Nanotechnology 2009, 20, 115103. [CrossRef]

62. Verma, A.; Stellacci, F. Effect of Surface Properties on Nanoparticle-Cell Interactions. Small 2010, 6, 12-21. [CrossRef] [PubMed]

63. Kenzaoui, B.H.; Vilà, M.R.; Miquel, J.M.; Cengelli, F.; Juillerat-Jeanneret, L. Evaluation of Uptake and Transport of Cationic and Anionic Ultrasmall Iron Oxide Nanoparticles by Human Colon Cells. Int. J. Nanomed. 2012, 7, 1275-1286.

64. Calero, M.; Gutiérrez, L.; Salas, G.; Luengo, Y.; Lázaro, A.; Acedo, P.; Morales, M.P.; Miranda, R.; Villanueva, A. Efficient and Safe Internalization of Magnetic Iron Oxide Nanoparticles: Two Fundamental Requirements for Biomedical Applications. Nanomed. Nanotechnol. Biol. Med. 2014, 10, 733-743. [CrossRef]

65. Lin, M.M.; Li, S.; Kim, H.-H.; Kim, H.; Lee, H.B.; Muhammed, M.; Kim, D.K. Complete Separation of Magnetic Nanoparticles via Chemical Cleavage of Dextran by Ethylenediamine for Intracellular Uptake. J. Mater. Chem. 2009, 20, 444-447. [CrossRef]

66. Xiao, Y.-D.; Paudel, R.; Liu, J.; Ma, C.; Zhang, Z.-S.; Zhou, S.-K. MRI Contrast Agents: Classification and Application (Review). Int. J. Mol. Med. 2016, 38, 1319-1326. [CrossRef] [PubMed]

67. Fernández-Barahona, I.; Muñoz-Hernando, M.; Ruiz-Cabello, J.; Herranz, F.; Pellico, J. Iron Oxide Nanoparticles: An Alternative for Positive Contrast in Magnetic Resonance Imaging. Inorganics 2020, 8, 28. [CrossRef]

68. Antal, I.; Strbak, O.; Khmara, I.; Koneracka, M.; Kubovcikova, M.; Zavisova, V.; Kmetova, M.; Baranovicova, E.; Dobrota, D. MRI Relaxivity Changes of the Magnetic Nanoparticles Induced by Different Amino Acid Coatings. Nanomaterials 2020, 10, 394. [CrossRef]

69. Marashdeh, M.W.; Ababneh, B.; Lemine, O.M.; Alsadig, A.; Omri, K.; El Mir, L.; Sulieman, A.; Mattar, E. The Significant Effect of Size and Concentrations of Iron Oxide Nanoparticles on Magnetic Resonance Imaging Contrast Enhancement. Results Phys. 2019, 15, 102651. [CrossRef]

70. Brisset, J.-C.; Desestret, V.; Marcellino, S.; Devillard, E.; Chauveau, F.; Lagarde, F.; Nataf, S.; Nighoghossian, N.; Berthezene, Y.; Wiart, M. Quantitative Effects of Cell Internalization of Two Types of Ultrasmall Superparamagnetic Iron Oxide Nanoparticles at 4.7 T and 7 T. Eur. Radiol. 2010, 20, 275-285. [CrossRef] [PubMed]

71. Zhang, Q.; Shan, W.; Ai, C.; Chen, Z.; Zhou, T.; Lv, X.; Zhou, X.; Ye, S.; Ren, L.; Wang, X. Construction of Multifunctional Fe3O4-MTX@HBc Nanoparticles for MR Imaging and Photothermal Therapy/Chemotherapy. Nanotheranostics 2018, 2, 87-95. [CrossRef] [PubMed]

72. Xie, T.; Chen, X.; Fang, J.; Xue, W.; Zhang, J.; Tong, H.; Liu, H.; Guo, Y.; Yang, Y.; Zhang, W. Non-Invasive Monitoring of the Kinetic Infiltration and Therapeutic Efficacy of Nanoparticle-Labeled Chimeric Antigen Receptor T Cells in Glioblastoma via 7.0-Tesla Magnetic Resonance Imaging. Cytotherapy 2021, 23, 211-222. [CrossRef] 